OECD Health Working Papers No. 89

\title{
The organisation of out-of- hours primary care in OECD countries
}

Caroline Berchet, Carol Nader 
Organisation de Coopération et de Développement Économiques

Organisation for Economic Co-operation and Development

09-Sep-2016

English text only

DIRECTORATE FOR EMPLOYMENT, LABOUR AND SOCIAL AFFAIRS

HEALTH COMMITTEE

\section{Health Working Papers}

OECD Health Working Paper No.89

THE ORGANISATION OF OUT-OF-HOURS PRIMARY CARE IN OECD COUNTRIES

Caroline Berchet and Carol Nader*

JEL classification: 118

Authorized for publication by Stefano Scarpetta, Director, Directorate for Employment, Labour and Social Affairs

(*) OECD, Directorate for Employment, Labour and Social Affairs, Health Division.

All health Working Papers are now available through the OECD's website at: http://www.oecd.org/els/health-systems/health-working-papers.htm

\section{JT03400366}

Complete document available on OLIS in its original format

This document and any map included herein are without prejudice to the status of or sovereignty over any territory, to the delimitation of international frontiers and boundaries and to the name of any territory, city or area. 


\title{
DIRECTORATE FOR EMPLOYMENT, LABOUR AND SOCIAL AFFAIRS
}

\author{
www.oecd.org/els
}

\section{OECD HEALTH WORKING PAPERS}

\author{
http://www.oecd.org/els/health-systems/health-working-papers.htm
}

OECD Working Papers should not be reported as representing the official views of the OECD or of its member countries. The opinions expressed and arguments employed are those of the author(s).

Working Papers describe preliminary results or research in progress by the author(s) and are published to stimulate discussion on a broad range of issues on which the OECD works. Comments on Working Papers are welcomed, and may be sent to the Directorate for Employment, Labour and Social Affairs OECD, 2 rue André-Pascal, 75775 Paris Cedex 16, France.

This series is designed to make available to a wider readership selected health studies prepared for use within the OECD. Authorship is usually collective, but principal writers are named. The papers are generally available only in their original language - English or French - with a summary in the other.

This document and any map included herein are without prejudice to the status of or sovereignty over any territory, to the delimitation of international frontiers and boundaries and to the name of any territory, city or area.

The statistical data for Israel are supplied by and under the responsibility of the relevant Israeli authorities. The use of such data by the OECD is without prejudice to the status of the Golan Heights, East Jerusalem and Israeli settlements in the West Bank under the terms of international law.

You can copy, download or print OECD content for your own use, and you can include excerpts from OECD publications, databases and multimedia products in your own documents, presentations, blogs, websites and teaching materials, provided that suitable acknowledgment of OECD as source and copyright owner is given. All requests for commercial use and translation rights should be submitted to rights@oecd.org. 


\section{ACKNOWLEDGEMENTS}

This paper has benefitted from comments from delegates of the OECD Health Committee. The authors are also grateful for comments by Ian Forde, Francesca Colombo, Mark Pearson and Stefano Scarpetta from the OECD Directorate of Employment, Labour and Social Affairs.

The opinions expressed in the paper are the responsibility of the authors and do not necessarily reflect those of the OECD or its Member Countries. 


\begin{abstract}
Out-of-hours $(\mathrm{OOH})$ services provide urgent primary care when primary care physician $(\mathrm{PCP})$ offices are closed, most often from $5 \mathrm{pm}$ on weekdays and all day on weekends and holidays. Based on a policy survey (covering 27 OECD countries) and the existing literature, the working paper describes the current challenges associated with the organisation of $\mathrm{OOH}$ primary care and reviews the existing models of delivering $\mathrm{OOH}$ primary care. The paper pays particular attention to policies which have been pursued to improve access and quality of $\mathrm{OOH}$ primary care.

Findings of the paper show that most OECD health systems report key challenges to provide $\mathrm{OOH}$ primary care in an accessible and safe way. These challenges relate to (i) PCPs' reluctance to practise due to high workload and insufficient remuneration; and (ii) geographical variations in access to OOH primary care within each health system. Together these challenges are leading sources of inappropriate hospital emergency department (ED) visits. Results also indicate that several models of $\mathrm{OOH}$ primary care exist alongside each other in the 27 OECD countries participating in the policy survey. Hospital EDs, rota groups and practice-based services remain the most common $\mathrm{OOH}$ arrangements, but there is a tendency to shift $\mathrm{OOH}$ primary care towards primary care centres and large-scale organisations known as general practice cooperatives (GPCs). A range of solutions have been implemented to improve access and quality of $\mathrm{OOH}$ primary care across OECD countries. These include providing organisational and financial support to PCPs; using other health care professionals (such as nurse practitioners), making $\mathrm{OOH}$ care participation compulsory, setting up a telephone triage system, using new technologies, and developing rich information systems.
\end{abstract}

\title{
RÉSUMÉ
}

La permanence des soins ambulatoires consiste à apporter une réponse aux besoins de soins non programmés aux heures de fermeture habituelle des cabinets de soins de premier recours; le plus souvent à partir de $17 \mathrm{~h}$ les soirs de la semaine et les week-ends. En se basant sur un questionnaire (renseigné par 27 pays Membres) et sur la littérature existante, ce document de travail examine les défis associés à l'organisation de la permanence des soins ambulatoires et décrit les principaux modèles d'organisation dans les pays de l'OCDE. Le document passe enfin en revue les récentes politiques adoptées par certains pays pour améliorer l'accès et la qualité des soins délivrés en dehors des heures ouvrées.

Les résultats du document de travail montrent que la majorité des pays de l'OCDE font face à des défis majeurs pour organiser la permanence des soins ambulatoires. Ces défis sont liés à (i) la réticence des médecins de premiers recours d'assurer la permanence des soins ambulatoires en raison notamment d'une charge de travail élevée et d'une rémunération insuffisante, et (ii) aux disparités géographiques dans l'accès aux soins en dehors des heures ouvrées. Ces défis favorisent le recours inapproprié aux services d'urgence hospitalière. Les résultats du questionnaire montrent, par ailleurs, que diffèrent modèles d'organisation existent côte à côte dans les 27 pays Membres ayant participé à l'enquête. Les urgences hospitalières, les systèmes de tour de garde, et la pratique individuelle des médecins de premier recours sont les modèles les plus souvent reportés par les pays de l'OCDE. Les centres de soins de santé et les coopératives de soins de premier recours ont un rôle grandissant pour assurer la permanence des soins ambulatoires. De nombreuses mesures ont été adoptées dans les pays de l'OCDE pour améliorer l'organisation et la qualité des soins délivrés en dehors des heures ouvrées. Ces mesures consistent à fournir un soutien organisationnel et financier aux médecins de premiers recours, à recourir à d'autres professionnels de santé (tels que les infirmiers praticiens), à rendre la participation à la permanence de soins obligatoire, à développer des services de soins offerts par téléphone ou par les nouvelles technologies, et à investir dans des systèmes d'information sophistiqués. 


\section{TABLE OF CONTENTS}

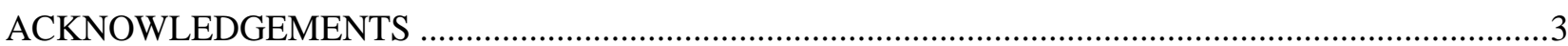

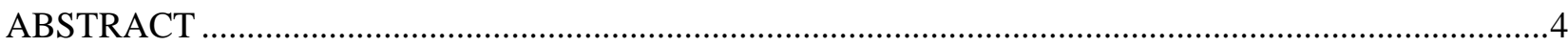

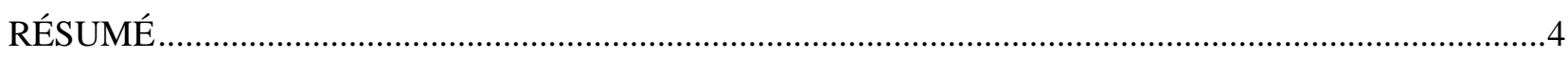

INTRODUCTION

1. THE PROVISION OF OUT-OF-HOURS PRIMARY CARE AT A GLANCE …..................................8

1.1. Out-of-hours primary care is critical for a well-functioning health system ....................................... 8

1.2. There are challenges related to the organisation of out-of-hours primary care ............................. 9

Many primary care physicians are reluctant to practise out-of-hours primary care ...............................

There are geographical variations in access to out-of-hours primary care ............................................10

1.3. ...which significantly increase inappropriate visits to hospital emergency departments ..................11

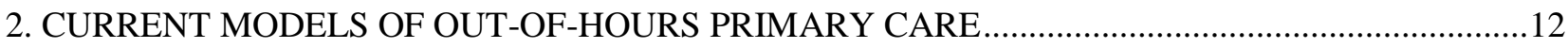

2.1. Hospital emergency departments complement rota groups and practice-based services in providing

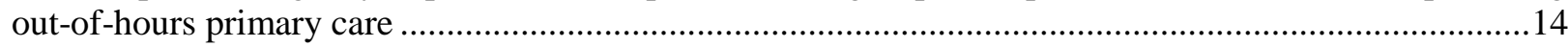

2.2 Deputising services are a less popular model for providing out-of-hours primary care in OECD

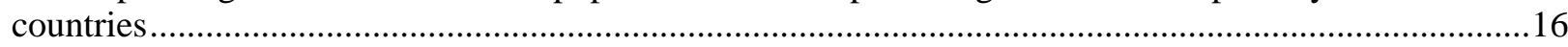

2.3. Out-of-hours primary care is increasingly being delivered in large-scale organisations ......................17

2.4. Most OECD countries have developed out-of-hours primary care centres .......................................18

2.5. Retail or private medical clinics located within stores are modestly developed................................20

3. POLICIES TO IMPROVE ACCESS TO AND QUALITY OF OUT-OF-HOURS PRIMARY CARE ..21

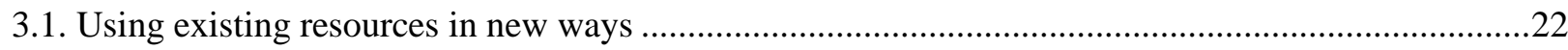

Providing organisational support can improve working conditions and make out-of-hours work more

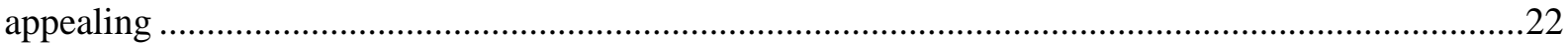

Rewarding primary care physicians may make their participation in out-of-hours care more appealing22 Other health professionals, such as paramedics and nurse practitioners, can help tackle workforce shortages and deliver more accessible out-of-hours care, particularly in rural and remote areas ..........24 It is compulsory for primary care physicians to participate in the provision of out-of-hours care in half

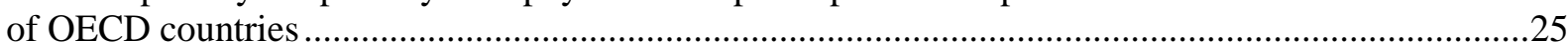

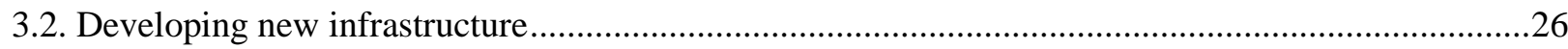
A telephone triage line or helpline and the use of other health technologies have the potential to relieve pressure on primary care physicians and to improve access to appropriate out-of-hours services ........26 Developing health information infrastructure underpinning out-of-hours primary care services is

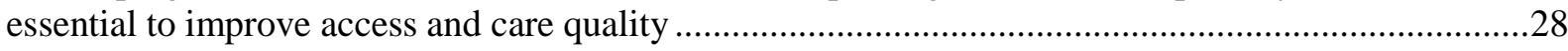

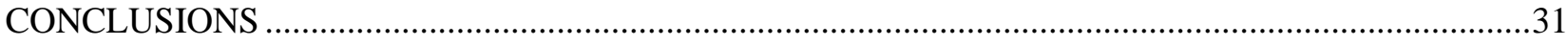

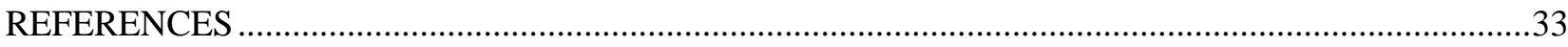


ANNEX 39

ANNEX A1. OECD POLICY SURVEY ON THE DELIVERY OF OUT-OF-HOURS PRIMARY CARE SERVICES .39

1. Organisation, planning and delivery of $\mathrm{OOH}$ primary care services ...............................................39

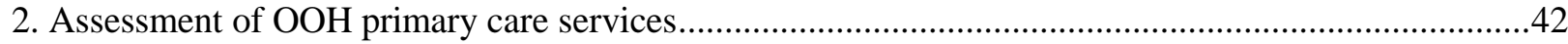

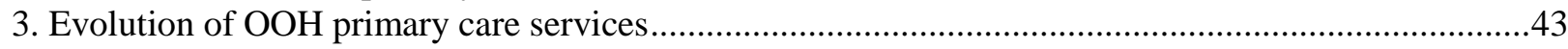

ANNEX A2. NUMBER OF COUNTRIES REPORTING DOMINANT OOH PRIMARY CARE

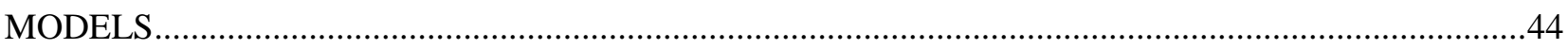

\section{Tables}

Table 1 Main models of out-of-hours primary care based on the policy survey ..................................13

Table 2. Most common out-of-hours primary care arrangements in OECD countries........................14

Table 3. Policy levers to improve access and quality of $\mathrm{OOH}$ primary care .....................................21

\section{Figures}

Figure 1. Arrangements for out-of-hours primary care and patient access, selected OECD countries.10 Figure 2. Number of countries reporting emergency departments as a dominant out-of-hours primary care model among those reporting practice-based services, rota groups or primary care centres as at least one dominant out-of-hours care model.

\section{Boxes}

Box 1. Definitions of the main out-of-hours primary care models in OECD countries ...........................12

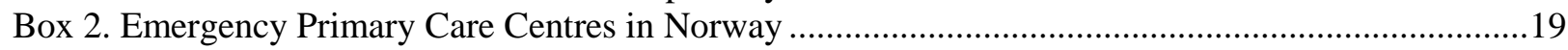

Box 3. The PIP After-Hours Incentives Programme in Australia........................................................23

Box 4. The PIP After-Hours Incentives Programme in Australia (cont.) ...............................................24

Box 5. Quality indicators for out-of-hours primary care services in Scotland .......................................29 


\section{INTRODUCTION}

1. Primary care services should strive to be person-centred, and respond to the needs of patients 24 hours a day, seven days a week. Patients sometimes require care at night and on weekends, because their symptoms cannot wait until the next business day. Out-of-hours $(\mathrm{OOH})$ services provide urgent primary care when primary care physician (PCP) offices are closed, most often from $5 \mathrm{pm}$ on weekdays and all day on weekends and holidays.

2. The organisation and delivery of $\mathrm{OOH}$ primary care is fundamental for a well-functioning health system. At the micro level, patients direct themselves to $\mathrm{OOH}$ primary care services because they are worried about their health status, and urgently need to receive advice and treatment. OOH primary care is also an important concern for health professionals because it affects their workload and working conditions. At the macro level, inappropriate organisation of $\mathrm{OOH}$ primary care has direct consequences for health care costs, notably through the use of more expensive resources such as hospital care. This paper shows that most OECD health systems are struggling to provide $\mathrm{OOH}$ primary care in an accessible and safe way. Most often, PCPs are reluctant to practise $\mathrm{OOH}$ because of high workload, insufficient remuneration and lack of personnel and organisational supports, especially in remote areas. OECD health systems try to deal with these issues by adopting a mix of models often working alongside one another including, for example, practice-based services, rota groups, deputising services, hospital emergency departments (EDs), primary care centres (PCCs) and general practice cooperatives (GPCs). OOH primary care has been evolving as health systems have been active in implementing solutions to manage its delivery. Health systems often react to $\mathrm{OOH}$ challenges with short-term responses rather than a coherent long-term strategy for $\mathrm{OOH}$ primary care provision.

3. The main purpose of this paper is to report on how $\mathrm{OOH}$ primary care services are organised across OECD countries, and how access and quality of $\mathrm{OOH}$ primary care can be improved. The paper is based on qualitative data collected through a policy survey sent to all OECD members' countries in March 2015 , completed by administrative sources from ministries of health and academics. The policy survey collected qualitative information on the organisation, planning and delivery of OOH primary care; assessment of current $\mathrm{OOH}$ arrangements; and evolution of $\mathrm{OOH}$ primary care services (see Annex A1). The results presented in this paper cover 27 OECD countries participating in the policy survey.

4. The paper is structured in three sections. The first section discusses the importance of $\mathrm{OOH}$ primary care and explores the current challenges associated with the organisation of $\mathrm{OOH}$ primary care across OECD countries. Section 2 reviews the existing models of delivering $\mathrm{OOH}$ primary care, and shows that several models of $\mathrm{OOH}$ primary care exist alongside one another in the 27 OECD countries participating in the policy survey. Section 3 pays particular attention to policies that have been pursued to improve access and quality of $\mathrm{OOH}$ primary care. The paper then draws conclusions on some broad policy recommendations for consideration. 


\section{THE PROVISION OF OUT-OF-HOURS PRIMARY CARE AT A GLANCE}

5. The provision of $\mathrm{OOH}$ primary care services has been a challenging policy issue for health systems. While $\mathrm{OOH}$ primary care is essential for a well-functioning health system, there are several challenges to guarantee high-quality and accessible $\mathrm{OOH}$ primary care. These challenges mostly relate to physicians' workload, sufficient remuneration and workforce shortages particularly in remote areas. Poorly functioning $\mathrm{OOH}$ primary care is a leading source of hospital ED visits for conditions that could be potentially treated in primary care settings.

\subsection{Out-of-hours primary care is critical for a well-functioning health system}

6. Across OECD countries, primary care often forms the front door to the health system. PCPs might act as health system gatekeepers, managing medical conditions when they can appropriately do so and referring patients to specialists and other health services when necessary. Primary care goes beyond services provided by doctors, to encompass other health professionals working in multidisciplinary teams. These teams, which may comprise PCPs, nurse practitioners and allied health professionals, can be considered "hubs of co-ordination" guiding patients through the health system (WHO, 2008).

7. Primary care services should strive to be patient-centred, and respond to the needs of patients 24 hours a day, seven days a week. Patients sometimes require care at night and on weekends, because their symptoms cannot wait until the next business day. When patients have timely access to primary care services outside of working hours, they can expect earlier diagnosis and treatment. While definitions can vary across $\mathrm{OECD}$ countries, $\mathrm{OOH}$ primary care is often considered care for medical conditions that can be managed outside of hospitals by a PCP, and that occur on weekdays between $5 \mathrm{pm}$ and $8 \mathrm{am}$ and on weekends and holidays (O'Malley et al, 2012; O’Malley, 2013). In some countries, the OOH period begins at $4 \mathrm{pm}$. There is diversity in the delivery of $\mathrm{OOH}$ primary care depending on patient need. OOH primary care can, for example, be delivered by telephone, at home, or in a health care facility.

8. Effective provision of $\mathrm{OOH}$ primary care is important for several reasons:

- First, in the face of the growing ageing population and the rising burden of chronic conditions, there is an increased emphasis on the need to provide patients with continuous and co-ordinated care. When $\mathrm{OOH}$ primary care is delivered by a patient's usual PCP, care fragmentation is less likely to occur mainly because health needs are assessed while taking into account patients' medical history (O’Malley, 2012). This increases the quality of health care services, reduces care duplication and decreases health care costs through minimising inappropriate care.

- Second, a lack of access to $\mathrm{OOH}$ health care presents a barrier to effective and timely treatment for patients. Ineffective $\mathrm{OOH}$ primary care can lead to the exacerbation of a medical condition and unnecessary hospitalisation (Weaver et al, 2014; Jerant et al, 2012). Offering extended access to primary care enables earlier diagnosis and treatment, which prevents complications and reduces avoidable health expenditures.

- Finally, the effective provision of $\mathrm{OOH}$ primary care limits the use of harmful tests, treatments and hospitalisations initiated by higher acuity providers such as hospital EDs (Jerant et al, 2012; Jones et al, 2010; Starfield, 2000). Compelling evidence shows that OOH primary care is associated with a relatively more judicious use of health care resources (such as more generic medication prescribing and less discretionary testing), with no adverse effects on patients' health 
outcomes. A more judicious use of health care resources related to the provision of $\mathrm{OOH}$ primary care is found to reduce overall patient health expenditures (Jerant et al, 2012).

\subsection{There are challenges related to the organisation of out-of-hours primary care...}

9. While demand for $\mathrm{OOH}$ primary care has been rising ${ }^{1}$ (Wijers et al, 2012; Salisbury, 2000; Munro et al, 2005), the provision of $\mathrm{OOH}$ primary care services is a challenging issue for governments. Key challenges in the provision of $\mathrm{OOH}$ primary care relate to PCPs' reluctance to practise due to increasing workloads and insufficient remuneration; and wide geographical variations in access to $\mathrm{OOH}$ primary care, particularly in rural areas with more limited medical infrastructure and workforce shortages.

\section{Many primary care physicians are reluctant to practise out-of-hours primary care}

10. Many PCPs are reluctant to practise $\mathrm{OOH}$ because of a desire for a better quality of life, high levels of stress, fear for their personal safety, increasing workloads and a lack of organisational supports. In some countries, these issues are exacerbated by a shortage of physicians, particularly in rural areas (Cragg et al, 1997; Leutgeb et al, 2014; Huibers et al, 2014; Thompson et al, 2004). Providers may be insufficiently compensated for working evenings and weekends, or at least have the perception that they are not adequately reimbursed for OOH work (O'Malley, 2013; Huber et al, 2011). There is growing recognition that a poorly managed $\mathrm{OOH}$ workload is unsustainable for PCPs and could compromise the safety of care that patients receive from fatigued doctors (Pooley et al, 2003).

11. The policy survey asked countries to report any barrier or resistance from health professionals to participate in $\mathrm{OOH}$ primary care. Financial remuneration and quality of life of PCPs were cited as key barriers to the provision of $\mathrm{OOH}$ care. The Czech Republic said there was a lack of financial motivation for PCPs. The Slovak Republic said PCPs had "no interest" in providing OOH care due to low payments, inadequate rest and risk of abuse by patients, and $\mathrm{OOH}$ services were "unnecessarily costly". Norway cited inconvenient long work hours, especially for physicians with children, too much work for PCPs, and a lack of security when working alone, especially in rural areas. Belgium reported similar issues with limited PCPs and a demanding workload, as well as violence against PCPs. Canada said there had been no specific resistance by PCPs to $\mathrm{OOH}$ care, but recent physician graduates favoured a balance between work and family obligations, and were less willing to sacrifice family time than previous generations. In Greece, a key weakness is the under-development of $\mathrm{OOH}$ primary care units, while Austria mainly has single PCP practices that rarely operate $\mathrm{OOH}$, and the hospital is a common entry point to the primary care system. Turkey cited high workload and lack of financial compensation.

12. Due to different national policies (and depending on the extent of these barriers), wide differences between countries are found regarding the availability of $\mathrm{OOH}$ primary health care services (Schoen et al, 2012; Schoen et al, 2011). Figure 1 shows between $34 \%$ and $95 \%$ of practices have $\mathrm{OOH}$ arrangements across selected OECD countries. PCPs in the United States (34\%) and Canada (45\%) were the least likely to report their practice provides $\mathrm{OOH}$ care arrangements. In countries where fewer PCPs participate in the provision of $\mathrm{OOH}$ primary care, access is more difficult for patients. Adult patients with complex needs from Canada (63\%) and the US (55\%) were the most likely to report obtaining OOH care was somewhat or very difficult. By contrast, in countries where more PCPs reported OOH arrangements, fewer patients reported such difficulties. In the Netherlands, for example, 95\% of practices have $\mathrm{OOH}$ arrangements and as a result, only $34 \%$ of patients reported $\mathrm{OOH}$ access difficulties. There are two exceptions to this trend: Australia and France. In Australia, 81\% of PCPs reported OOH arrangements, but

1. Rising burden of chronic conditions, difficulty in obtaining same-day appointments with a PCP, a lack of transport, and work commitments are drivers of higher demand for $\mathrm{OOH}$ primary care (Tenbensel et al, 2014; Den Boer-Woltersa et al, 2010; Flarup et al, 2014; Buja et al, 2015). 
$56 \%$ of patients reported $\mathrm{OOH}$ access difficulties. Another survey of Australian PCPs shows that the proportion reporting they worked in practices providing their own after-hours services declined from $36 \%$ in 2004-05 to 31\% in 2013-2014 (Britt et al, 2014). In France, 76\% of PCPs had OOH arrangements, but $55 \%$ of patients reported $\mathrm{OOH}$ access difficulties. These two exceptions perhaps reflect geographical variations in access within countries.

Figure 1. Arrangements for out-of-hours primary care and patient access, selected OECD countries

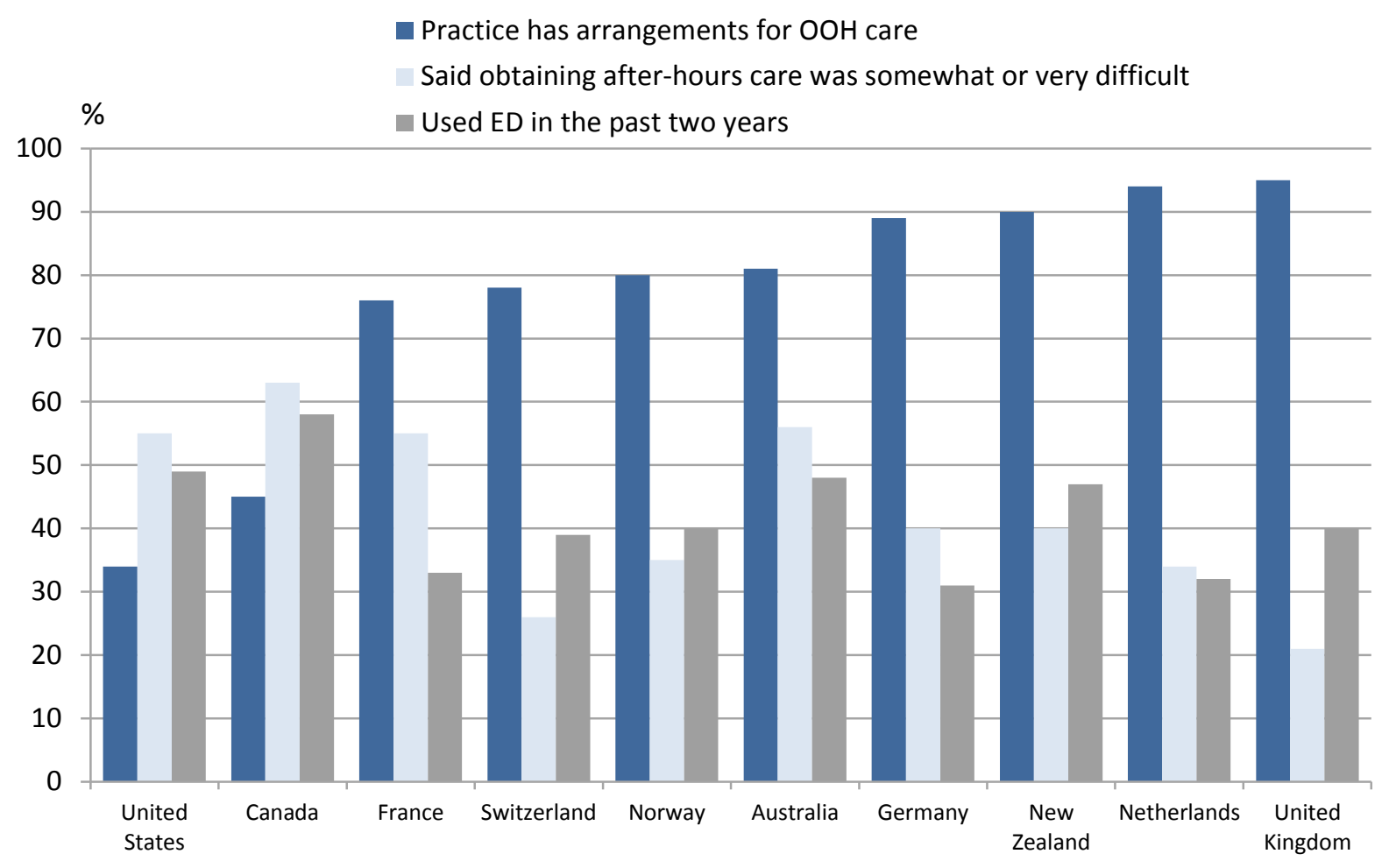

Source: Sources: Data compiled from Schoen, C. et al. (2011), "New 2011 survey of patients with complex care needs in eleven countries finds that care is often poorly coordinated", Health Affairs, Vol. 30, No. 12, pp. 2437-2448. doi:10.1377/hlthaff.2011.0923; and Schoen, C. et al. (2012), "A survey of primary care doctors in ten countries shows progress in use of health information technology, less in other areas", Health Affairs, Vol. 31, No. 12, pp. 2805-2816. doi:10.1377/hlthaff.2012.0884

\section{There are geographical variations in access to out-of-hours primary care}

13. Geography is a key determinant of $\mathrm{OOH}$ access. Due to long travelling distance, geography might constitute barriers of cost, time and inconvenience for patients. These barriers reflect the poor availability of health care resources in rural and remote areas. Geographical variation in access to $\mathrm{OOH}$ primary care is a source of concern since it can lead to delays in care, compromise patient safety and result in health complications.

14. Available evidence shows that, all things being equal, patients in rural areas have fewer contacts and consultations with $\mathrm{OOH}$ primary care compared to their counterparts in urban areas (Turnbull et al, 2008). Rural patients often delay seeking help until their PCP is available in-hours, when they are not on call (Campbell et al, 2006). In a similar vein, increasing travel distance is associated with lower use of $\mathrm{OOH}$ services, even for the most acute cases (Raknes et al, 2013). Together the body of evidence suggests that in rural and remote areas, access to $\mathrm{OOH}$ primary care is more challenging because of more limited 
medical infrastructure and workforce shortages, which overall increases travelling distance for sparsely distributed populations.

15. The policy survey asked countries whether there were geographical differences in the organisation of $\mathrm{OOH}$ services in their health systems. Norway indicated a clear lack of recruitment in rural areas. Travel distances were reported as too long and there were too few doctors on call in rural areas. Germany also cited the burden on PCPs in under-served regions. Belgium, Israel, and Poland reported wide geographical variations in access to $\mathrm{OOH}$ primary care, with particular difficulties in rural areas where there is a lack of medical facilities and workforce shortages. In Australia, significant variation in $\mathrm{OOH}$ primary care visits across the country is also found (NHPA, 2013). OOH visits in 2011-12, for example, ranged from 0.05 per person in the remote Kimberley-Pilbara and regional New England areas, to a high of 0.79 in suburban south-western Melbourne.

\section{3. ...which significantly increase inappropriate visits to hospital emergency departments}

16. Many patients who cannot access OOH primary care seek care in hospital EDs. "Inappropriate" or non-urgent visits are characterised by low urgency problems and require other health services than emergency admission (Berchet, 2015). Such inappropriate ED visits are for conditions that could be better managed in the community by a PCP or by the broader primary care clinical team. Inappropriate ED visits are a source of concern for several reasons. First, they consume ED inputs and jeopardise the prompt treatment of more seriously ill patients. Second, they reduce the quality of care through prolonged waiting times and delay diagnosis and treatment. Third, they lead to overcrowding and disrupt patient flow within hospitals, which might adversely affect quality and outcomes of care.

17. Studies indicate between $12 \%$ and $56 \%$ of ED visits are to patients with non-serious problems that could be better managed in the community by a PCP. Inappropriate visits to EDs account for nearly $12 \%$ of ED visits in the United States and England, 20\% in Italy and France, 25\% in Canada, 31\% in Portugal, 32\% in Australia and 56\% in Belgium (Berchet, 2015).

18. Several factors determine the inappropriate use of EDs. Beyond patients' preferences, as well as patients' consultation patterns and perceptions of the appropriate place for treatment, there is compelling evidence suggesting that shortage of $\mathrm{OOH}$ primary care services are positively associated with a higher demand for emergency care. Countries with more robust after-hours options for care, as well as those with short waiting times for a primary care appointment, seem less likely to have a high volume of ED visits. By contrast, countries where patients are unable to obtain a rapid primary care appointment or where access to $\mathrm{OOH}$ services outside hospital EDs is limited display a high volume of ED visits (Berchet, 2015). This tendency is confirmed by Figure 1 above. The use of EDs in the past two years is likely to be more important in countries reporting the lowest rates of practices having $\mathrm{OOH}$ arrangements. Canada and the United States for example report (i) the highest rates of patients reporting ED visits in the past two years and (ii) the lowest rates of PCPs having $\mathrm{OOH}$ arrangements. 


\section{CURRENT MODELS OF OUT-OF-HOURS PRIMARY CARE}

19. Seven main models of OOH primary care exist alongside one another in the 27 OECD countries participating in the policy survey: practice-based services, rota groups, deputising services, hospital emergency departments (EDs), primary care centres (PCCs), general practice cooperatives (GPCs) and retail clinics (see Box 1 for definitions). As this section emphasises, among the countries participating in the policy survey, hospital EDs, rota groups and practice-based services are the most common $\mathrm{OOH}$ arrangements. When countries rely on rota groups or practice-based services, hospital EDs to some extent are more likely to manage primary care patients during $\mathrm{OOH}$. However, there is a tendency to shift $\mathrm{OOH}$ primary care toward PCCs and large-scale organisations such as GPCs, while deputising services and retail clinics are more modestly developed across OECD countries.

\section{Box 1. Definitions of the main out-of-hours primary care models in OECD countries}

Practice-based services

Rota groups

Deputising services

Emergency departments

Primary care centres: variations include after-hours walk-in primary care centres, minor injury units and urgent care centres

General practice cooperatives

Retail or medical clinics located within retail stores
Physicians in individual or group practices look after their own patients $\mathrm{OOH}$.

Several physicians within a practice or call rotation look after their own and each other's patients during $\mathrm{OOH}$ times.

Commercial companies that employ doctors and nurses to take over a general practice's provision of $\mathrm{OOH}$ care through an outsourcing or contracting arrangement.

Hospital emergency departments manage patients with primary care conditions.

Facilities attached or not to hospitals where patients can visit without an appointment for minor injuries or illnesses. Such facilities can be nurseled or GP-led.

Large-scale groups of PCPs providing $\mathrm{OOH}$ care in a region. Services include telephone triage, clinic consultations and house calls. PCPs take turns being on $\mathrm{OOH}$ duty for the patients of all participating PCPs.

Retail or medical clinics located within retail stores (grocery stores or pharmacies) staffed by nurse practitioners or other health professionals. 
Table 1 Main models of out-of-hours primary care based on the policy survey

\begin{tabular}{|c|c|c|}
\hline Main out-of-hours care models & Countries & $\mathbf{N}$ \\
\hline Practice-based services & $\begin{array}{c}\text { Australia, Austria, Belgium, Canada, Chile, Czech } \\
\text { Republic, Estonia, Finland, France, Germany, } \\
\text { Greece, Mexico, the Netherlands, Slovak Republic, } \\
\text { Switzerland, Turkey, the United Kingdom, the } \\
\text { United States }\end{array}$ & 18 \\
\hline Rota groups & $\begin{array}{c}\text { Australia, Austria, Belgium, Canada, Chile, France, } \\
\text { Germany, Hungary, Iceland, Norway, Slovak } \\
\text { Republic, Slovenia, Spain, Switzerland, Turkey, the } \\
\text { United States }\end{array}$ & 16 \\
\hline Deputising services & $\begin{array}{c}\text { Australia, Belgium, Chile, Hungary, Israel, Slovak } \\
\text { Republic, Slovenia, the United Kingdom, the United } \\
\text { States }\end{array}$ & 9 \\
\hline Hospital emergency departments & $\begin{array}{l}\text { Australia, Austria, Belgium, Canada, Chile, Czech } \\
\text { Republic, Denmark, Estonia, Finland, France, } \\
\text { Germany, Greece, Iceland, Israel, Mexico, the } \\
\text { Netherlands, Poland, Slovak Republic, Slovenia, } \\
\text { Spain, Switzerland, Turkey, the United Kingdom, the } \\
\text { United States }\end{array}$ & 24 \\
\hline $\begin{array}{l}\text { Primary care centres (PCCs) such as } \\
\text { after-hours walk-in primary care centres, } \\
\text { minor injury units (MIUs) /urgent care } \\
\text { centres (UCCs) }\end{array}$ & $\begin{array}{c}\text { Australia, Austria, Belgium, Canada, Chile, Czech } \\
\text { Republic, Denmark, France, Iceland, Israel, } \\
\text { Luxembourg, Mexico, Norway, Poland, Slovak } \\
\text { Republic, Slovenia, Spain, Switzerland, Turkey, the } \\
\text { United Kingdom, the United States }\end{array}$ & 21 \\
\hline General practice cooperatives (GPCs) & $\begin{array}{c}\text { Australia, Belgium, Denmark, France, the } \\
\text { Netherlands, Switzerland }\end{array}$ & 6 \\
\hline Retail or medical clinics & $\begin{array}{c}\text { Belgium, Canada, Chile, Mexico, the Netherlands, } \\
\text { the United Kingdom, the United States }\end{array}$ & 7 \\
\hline
\end{tabular}

Source: OECD Policy Survey on the delivery of out-of-hours primary care services (2015) 
Table 2. Most common out-of-hours primary care arrangements in OECD countries

\begin{tabular}{|c|c|}
\hline Country & Dominant models of out-of-hours primary care \\
\hline Australia & Practice-based service \\
\hline Austria & Practice-based service, hospital ED, rota group \\
\hline Belgium & Rota group, PCC \\
\hline Canada* & Hospital ED, practice-based service \\
\hline Chile & PCC \\
\hline Czech Republic & Hospital ED (urban areas), PCC (rural areas or small cities) \\
\hline Denmark & GPC \\
\hline Estonia & Practice-based service, hospital ED \\
\hline Finland & Hospital ED \\
\hline France & Rota group, hospital ED \\
\hline Germany & Rota group \\
\hline Greece & Hospital ED, practice-based service \\
\hline Hungary & Rota group \\
\hline Iceland & Rota group, hospital ED \\
\hline Israel & Hospital ED, PCC (walk-in clinic) \\
\hline Luxembourg & PCC \\
\hline Mexico & Hospital ED, practice-based service \\
\hline Netherlands & GPC \\
\hline Norway & PCC \\
\hline Poland & PCC, hospital ED \\
\hline Slovak Republic & Practice-based service \\
\hline Slovenia & Rota group, hospital ED \\
\hline Spain & Rota group (rural areas), PCC (urban areas) \\
\hline Switzerland & GPC (rural and urban areas), hospital ED (urban areas) \\
\hline Turkey & Practice-based service, hospital ED (urban areas) \\
\hline United Kingdom & Deputising service, PCC \\
\hline United States & Rota group, hospital ED \\
\hline
\end{tabular}

Note: *In Canada, the characteristics and the organisation of $\mathrm{OOH}$ primary care services differ at the provincial level. The data and facts reported in the paper are only approximations for the majority of provinces.

Source: OECD Policy Survey on the delivery of out-of-hours primary care services (2015)

\subsection{Hospital emergency departments complement rota groups and practice-based services in providing out-of-hours primary care}

20. Although different models for organising $\mathrm{OOH}$ primary care exist alongside one another across OECD countries (Table 1), the policy survey results show that hospital EDs, rota groups and practicebased services are the most common $\mathrm{OOH}$ arrangements (Table 2, Annex A2). While debate continues about their "inappropriate" use, EDs continue to be used to manage primary care patients in several OECD countries. Even in some countries where this is not encouraged, citizens can freely attend an ED. The use of EDs for OOH primary care is reported in 24 OECD countries (Table 1), of which 15 report the ED is at least one dominant model (Table 2 and Annex A2) (Austria, Canada, Czech Republic, Estonia, Finland, France, Greece, Iceland, Israel, Mexico, Poland, Slovenia, Switzerland, Turkey, and the United States). Hospital EDs are more often cited as a dominant model in countries that report practice-based services and rota groups as also dominant models (Figure 2). 
Figure 2. Number of countries reporting emergency departments as a dominant out-of-hours primary care model among those reporting practice-based services, rota groups or primary care centres as at least one dominant out-of-hours care model

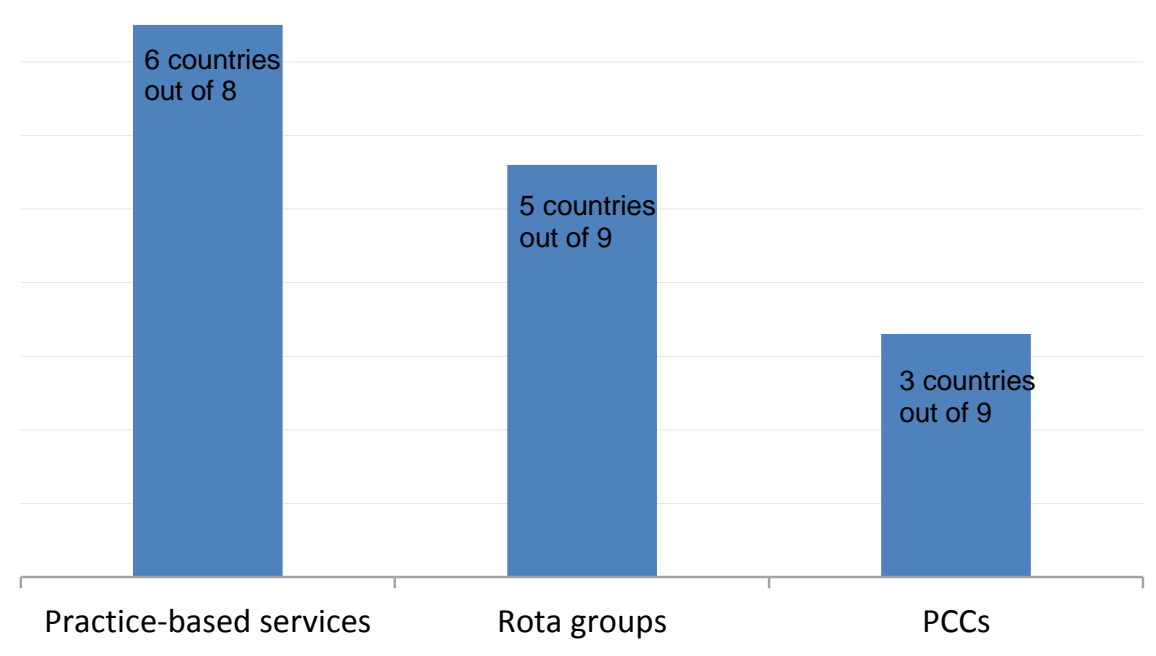

Source: OECD Policy Survey on the delivery of out-of-hours primary care services (2015). Note: Among the countries that cite practice-based services as at least one dominant $\mathrm{OOH}$ model, six countries also report hospital EDs as another dominant mode of provision.

21. The rota group is reported in 16 OECD countries (Table 1) and among these, nine countries report rota groups as dominant $\mathrm{OOH}$ models (Austria, Belgium, France, Germany, Hungary, Iceland, Slovenia, Spain, and the United States) (Table 2, Annex A2). The policy survey shows that among this latter group, five countries also report EDs as a predominant mode of $\mathrm{OOH}$ primary care (Austria, France, Iceland, Slovenia, the United States) (Figure 2). This is the case in France for example, where rota groups are reported as the dominant model for organising $\mathrm{OOH}$ primary care. Regional Health Authorities are responsible for defining geographical areas to be covered by the rota group according to local constraints. In each geographical area, PCPs register on a voluntary basis to take turns and to look after their own and each other's patients during OOH. However, the Public Health Regulation (Code de la Santé Publique) specifies that depending on the demand for and the supply of health care services within the geographical area, $\mathrm{OOH}$ primary care can also be organised through hospital EDs. This is especially the case from midnight to 8 am during weekdays, when demand for health care services is found to be very low. The decision to organise $\mathrm{OOH}$ primary care within hospital EDs falls under the Regional Health Authorities according to population health needs and available resources.

22. In the United States, rota groups are also the dominant mode for providing $\mathrm{OOH}$ primary care (although numerous other strategies are developed as outlined in Table 1). Available evidence and the policy survey, however, suggest that access to $\mathrm{OOH}$ primary care is in practice limited and often provided in hospital EDs.

23. In a similar vein, practice-based services, where the individual PCP looks after their own patients, is a popular model across OECD countries. The use of $\mathrm{OOH}$ practice-based services is reported in 18 OECD countries (Table 1) and eight countries cite this as at least one dominant model (Australia, Austria, Canada, Estonia, Greece, Mexico, Slovak Republic, Turkey) (Table 2, Annex A2). The policy survey shows that among this group, six countries also report hospital EDs as a dominant mode of provision (Austria, Canada, Estonia, Greece, Mexico and Turkey) (Figure 2). 
24. In Canada, the characteristics of $\mathrm{OOH}$ care differ between provinces. Practice-based services, where physicians look after their rostered patients directly or through agreements between practices and other individual physicians, are possible in some provinces and territories. However, about $50 \%$ of the population in Canada uses the ED as a portal for $\mathrm{OOH}$ care. That includes the $15 \%$ of patients without a family physician and all the patients with a family physician who does not offer $\mathrm{OOH}$ primary care alternatives. In Estonia, practice-based medicine was introduced in 2014 as a new service provided by the Estonian Health Insurance Fund (EHIF). OOH appointments with family physicians and nurses are now made possible in two counties. In 2014, there were $4462 \mathrm{OOH}$ visits made to family physicians and 4960 $\mathrm{OOH}$ visits made to family nurses, with a significant increase in 2015. In spite of the new scheme, $\mathrm{OOH}$ primary care services are still provided by hospital EDs (Põlluste et al, 2013), due to lack of supply in other counties, patient preference and self-referrals to hospital EDs.

25. Overall, findings from the survey indicate that hospital EDs complement rota groups and practice-based services to provide $\mathrm{OOH}$ primary care. This is, to a lesser extent, also the case in countries relying on PCCs. Among countries that report PCCs as at least one dominant mode of provision (nine countries), three also cite hospital EDs as another dominant model (Figure 2, Table 2, Annex A2).

\subsection{Deputising services are a less popular model for providing out-of-hours primary care in OECD countries}

26. Deputising services, where commercial companies employ doctors and nurses to take over a general practice's provision of $\mathrm{OOH}$ care through an outsourcing or contracting arrangement, are established in nine OECD countries (Australia, Belgium, Chile, Hungary, Israel, Slovak Republic, Slovenia, the United Kingdom, the United States). However, only the United Kingdom cites deputising services as at least one dominant model (Table 2, Annex A2).

27. Since 2004, GPs in the United Kingdom have been able to opt out of providing OOH care, and most of them have done so. In $90 \%$ of cases, GPs opt out of responsibility for $\mathrm{OOH}$ service provision and enable their Clinical Commissioning Group (CCG) to contract other services to provide $\mathrm{OOH}$ care. Where services have opted in, the GPs can provide $\mathrm{OOH}$ care directly or subcontract to other bodies. Where services have opted out, CCGs contract with a range of service providers such as:

- Social enterprises (often former cooperatives of GPs) which hold $49 \%$ of contracts;

- Commercial organisations (such as Care UK) which hold 31\% per cent of contracts;

- National Health Service (NHS) bodies (such as ambulance trusts) which hold $20 \%$ of contracts.

28. Deputising services are becoming very popular in Australia. Such services are organised through the approved Medical Deputising Service (MDS), which is managed by the Department of Health. MDS enables GPs to contract out the OOH component of their patients' care to other practices. It uses the same facilities and processes that ensure continuous access to care and continuity of patient care. MDS also can provide home visits, medical advice and telephone triage services. Due to important challenges around geographical differences in access to $\mathrm{OOH}$ primary care services, there has been significant growth in deputising services over recent years in Australia. The proportion of GPs working in practice solely using deputising services for the provision of $\mathrm{OOH}$ care increased from $35 \%$ in $2004-05$ to $47 \%$ in $2013-14$ (Britt et al., 2014). The Department of Health expects to expand the pool of medical practitioners who work for an MDS.

29. The literature shows that deputising services lead to similar patient health outcomes compared to general practices (Mckinley et al, 1997). Regarding the process of care, evidence shows that deputising 
doctors are more likely to give home visits and to issue prescriptions, but are less likely to give telephone advice compared to general practice doctors (Cragg et al, 1997). McKinley et al. (1997) and Warren et al. (2015) show that patient satisfaction rates are lower with the experience of deputising services than general practice, due mainly to a lower level of trust and confidence in deputising clinicians. On the physician side, a systematic review suggests deputising services increase immediate medical workload because of the lower use of telephone advice and the higher home visiting rate (Leibowitz et al, 2003). PCPs working in GPCs were also found to be more satisfied than those in deputising services (Salisbury, 1997).

\subsection{Out-of-hours primary care is increasingly being delivered in large-scale organisations}

30. Some countries have shifted $\mathrm{OOH}$ primary care toward large-scale organisations. General practices cooperatives (GPCs) are large-scale groups of PCPs, supported by additional personnel, providing after-hours primary care including telephone advice, offices for face-to-face consultations, and home visits. The policy survey indicates that GPCs are established in six OECD countries (Australia, Belgium, Denmark, France, the Netherlands and Switzerland) (Table 1), and are reported as a dominant model in three countries (Denmark, the Netherlands and Switzerland).

31. In the Netherlands, the GPC is the unique model for organising OOH primary care. GPCs are multiple clinics cooperating on a central location called the "“huisartsenpost" (HAP) staffed by PCPs who carry out both telephone and face-to-face consultations. The organisation of $\mathrm{OOH}$ primary care is the same in urban and rural areas. Patients are first required to call the GPC to get medical advice. Depending on the medical condition, the PCP will give self-care advice so that the patient stays at home and can visit primary care during normal working hours. An alternative option is to ask the patient to call back if the health problem is getting worse, and to make a home visit. In case of more urgent health conditions, the PCP advises the patient to go to the GPC or go directly to the hospital ED or call an ambulance. Patients are discouraged from visiting the GPC in case of small complaints that do not require immediate attention. In case of minor ailments and without any referral, the patient will be asked to consult during normal office hours. In 2014, there were 122 GPCs in the Netherlands. Nearly 1.48 million hours of service have been performed, representing around four million medical acts. The total cost of the HAP is estimated at around EUR 284.4 million, which represents EUR 17.11 per inhabitant per year.

32. Some regions in the Netherlands have a model that integrates a GPC and an ED, with one triage point determining which service patients attend, so that patients cannot go directly to the ED (Thijssen et al, 2013). Several studies in the Netherlands found the integrated model has the potential to reduce health system costs, as it was associated with a reduction in patient self-referrals to the ED (Kool et al, 2008; Van Uden et al, 2005a; Thijssen et al, 2013).

33. In Belgium, such cooperatives are called General Practitioners Posts (GP Posts), which operate in well-defined territories covering the entire country. They are found in both rural and urban areas. GP posts provide $\mathrm{OOH}$ primary care during weekends (from Friday $7 \mathrm{pm}$ to Monday $8 \mathrm{am}$ ) and on public holidays. Services provided are face to face consultations, medical advice by phone and home visits. GPCs are frequently used, covering nearly $70 \%$ of the Belgian population. There were expected to be 48 GP Posts in Belgium by the end of 2015. In Switzerland, GPCs are found in rural and urban areas, while in urban areas hospital EDs also assume responsibility for urgent $\mathrm{OOH}$ primary care.

34. In France, the "Maisons médicales de garde" (MMG) are similar to what are known as GPCs in other OECD countries. MMGs have been established as a network of GPs to provide emergency care in the community setting and during $\mathrm{OOH}$. They are designed to provide medical services to walk-in patients with minor injuries or illnesses and only during $\mathrm{OOH}$. Most often, they have been established near the hospital ED to encourage patients' referral. While the Regional Health Agencies promote the establishment of MMG throughout the country, their development and use remain limited (Cour des comptes, 2013). In 
2013, there were only 369 MMG (covering about $23 \%$ of OOH care services), with a wide variation in their availability across the country (Cour des comptes, 2014).

35. Overall, GPCs are found to provide safe and accessible care for patients and to reduce physician workload. A large body of evidence shows high patient satisfaction with GPCs ranging from $72 \%$ to $86 \%$ (Van Uden et al, 2005b; Christensen and Olesen, 1998; Hansen and Munck, 1998; Smith et al, 2001). On the supply side, GPCs reduce PCPs' workload and increase their level of satisfaction. At the macro level, GPCs reduce the use of hospital emergency resources by shifting patient flow from emergency care to primary care settings.

\subsection{Most OECD countries have developed out-of-hours primary care centres}

36. Primary care centres (PCCs), walk-in clinics, minor injury units (MIUs) and urgent care centres (UCCs) are very similar facilities designed to provide $\mathrm{OOH}$ primary care services for patients with minor injuries or illness (Berchet, 2015). Care is often provided to patients on a walk-in basis, and is often considered a substitute to home visits and non-urgent hospital ED visits. Such primary care facilities can be nurse-led or PCP-led, and can be standalone centres or attached to hospital EDs.

37. Such centres are becoming very popular in OECD countries. Results from the policy survey demonstrate that 21 OECD countries have established some form of PCC (Australia, Austria, Belgium, Canada, Chile, Czech Republic, Denmark, France, Iceland, Israel, Luxembourg, Mexico, Norway, Poland, Slovak Republic, Slovenia, Spain, Switzerland, Turkey, the United Kingdom, the United States). Nine countries have listed PCCs as at least one dominant model (Belgium, Chile, Czech Republic, Israel, Luxembourg, Norway, Poland, Spain, and the United Kingdom) of which three countries also report hospital EDs as another dominant $\mathrm{OOH}$ model (Czech Republic, Israel, Poland) (Figure 2, Table 2, Annex A2).

38. In Chile, Emergency Primary Care Services (Servicios de Atención Primaria en Urgencias SAPU) operate both during normal office hours and $\mathrm{OOH}$. They work mainly from $5 \mathrm{pm}$ to midnight on weekdays and 24/7 on weekends and holidays. They give medical care, nursing care, drug delivery and possible transfers. Beyond SAPU, a network of Rural Emergency Services (Servicios de Urgencia Rural, SUR) has been developed. Around 158 SUR have been established in rural communities. In geographical areas of more than 10000 inhabitants, walk-in appointments in SUR are made possible until 10pm on working days. After 10pm and on weekend, PCPs are only on call. In areas of less than 10000 inhabitants, PCPs are only on call and an ambulance is arranged if medically necessary. SAPU and SUR are widely promoted by the government, and as a result of their success attendance at both is rising.

39. In Iceland, a walk-in PCC called Læknavaktin has been recently set up in the capital area to provide $\mathrm{OOH}$ primary care. The centre consists of PCPs, nurse consultations and home visits. In a similar vein, patients in Poland in need of urgent medical care outside normal office hours can attend a primary care unit. These units operate from $6 \mathrm{pm}$ to $8 \mathrm{am}$ as well as on weekends and holidays. There are around 400 primary care units in Poland, which are, according to national authorities, frequently used by patients for minor conditions. In Spain, there are around 2000 primary care centres to provide $\mathrm{OOH}$ care for emergency needs. They are available on a walk-in basis from $5 \mathrm{pm}$ (although some of them start at 9pm). The development of such primary care centres in Spain is also highly promoted by the government. This is also the case in Israel, where after-hours PCCs are also available in some towns. In Luxembourg, PCCs are the only mode of provision for $\mathrm{OOH}$ primary care. One $\mathrm{OOH}$ PCC is established in each of the three geographical areas. The staff assigned to $\mathrm{OOH}$ PCCs increase with the number of inhabitants in each region. In France, PCCs are called "Centre de soins non programmés". They are set up at the initiative of PCPs who choose to organise their practice on a walk-in basis, with extended hours. According to national authorities, however, $\mathrm{OOH}$ primary care cannot solely rely on these facilities because they are rare and 
unevenly distributed over the country. In Austria, OOH primary care units have been legally possible for a few years, either in the private outpatient sector or in hospitals. So far they are not widely developed across the country. Recent evaluations show a high degree of satisfaction for both patients and health care providers. In Norway, Emergency Primary Care Centres are similar to PCCs. As Box 2 emphasises, Norwegian patients are not allowed to self-refer to hospital EDs, and have no other alternative but to attend or contact a PCC.

\section{Box 2. Emergency Primary Care Centres in Norway}

Norway has a separate $\mathrm{OOH}$ system within the primary care sector with responsibility for managing minor injuries or illnesses. Emergency Primary Care Centres (EPCCs - legevaktstasjon) are similar to the PCC and urgent care centre models. Patients may go directly to an EPCC without an appointment, but may also receive advice on the telephone.

Due to Norway's strict two-tiered health care system, patients are not allowed to present themselves directly to hospital EDs. Out of normal practice hours, they have to contact an EPCC. In cases of emergency situations, citizens must call the emergency number 113 to the Emergency Medical Communication Centre and, if necessary, an ambulance will take them to hospital.

PCPs are responsible for the urgent care of their own patients only in-hours, but not $\mathrm{OOH}$. However, the same PCPs are expected to participate in the EPCCs. Local authorities have overall responsibility for both inhours and $\mathrm{OOH}$ primary care services, and have to ensure emergency care services are available 24/7. In larger municipalities, there are also EPCCs in-hours.

Source: Information provided by Norwegian authorities.

40. Interestingly, the policy survey indicates that such PCCs are not promoted in Canada and the United States. In Canada, several provinces have set up urgent care centres (UCCs) as a service option to provide intermediate level of service between family physician offices, medical clinics and hospital EDs for patients who require more intensive resources than those available in a typical physician office. They are most often available 24 hours a day, seven days a week. Most patients with no family physician or with a family physician who does not offer alternatives for $\mathrm{OOH}$ care use these UCCs for both their regular and urgent care. Because of their limited capacity to provide continuity of care and to co-ordinate service provision across the health care sector, national authorities do not encourage the use of UCCs. This is also the case in the United States, where PCCs have become increasingly popular due to difficulty in accessing timely $\mathrm{OOH}$ primary care because of long waiting times and a lack of PCPs' $\mathrm{OOH}$ availability. The use of such models is not promoted because it detracts from efforts to co-ordinate care and to increase continuity of provider-patient relationships.

41. Evidence of the impact of $\mathrm{OOH}$ primary care facilities is conflicting. While several studies show that $\mathrm{OOH}$ primary care centres provide accessible and high-quality care (Grant et al., 2002; Salisbury, 2003), other evidence demonstrates that PCCs do not contribute to shorter waiting times for patients (Maheswaran et al, 2007) and are associated with lower satisfaction rates than general practice (Hutchison et al, 2003). There is little evidence to suggest that walk-in centres reduce ED activity by managing patients with minor injuries or illnesses. Studies conducted in Australia, England and New Zealand do not support this hypothesis (Fry, 2011; Parker et al, 2011; Salisbury et al, 2002; Tenbensel et al, 2013).

42. Overall, there are three particular concerns related to the development of emergency PCCs. First, the setting up of such facilities might generate greater service availability, which increases unwarranted demand for health care services and might result in duplication of care (Tan and Mays, 2014; Pinchbeck, 2014). Second, such facilities might also cause confusion among patients about where to go for care. When the array of primary emergency care services is large, patients might become uncertain about how to access $\mathrm{OOH}$ primary care. In England for example, Monitor (2014) shows that (i) patients use walk-in clinics in addition to other services for the same medical problem and (ii) the wide development of such facilities has 
caused patients confusion about where to seek appropriate treatment. Third, and as emphasised by Canadian and American authorities, such facilities most often have limited capacity to ensure continuity and co-ordinated care across the health sector, unless electronic health records are used. These concerns are not specific to all OECD countries, and mostly depend on a country's cultural context (such as patient preference), infrastructural resources and supply of health services.

\subsection{Retail or private medical clinics located within stores are modestly developed}

43. Retail or private medical clinics are located in commercial settings, such as pharmacy or grocery stores. They provide medical care for minor conditions without appointment and with relatively short waiting times. Most of them operate 12 hours a day during the work week and eight hours on Saturday and Sunday (McKinlay and Marceau, 2012). The policy survey indicates that retail clinics are established in seven OECD countries (Belgium, Canada, Chile, Mexico, the Netherlands, the United Kingdom and the United States).

44. This mode of provision is more recent in Belgium and the Netherlands. In Belgium, the medical clinic has been set up in a metro station, while in the Netherlands the $\mathrm{OOH}$ primary care facility has opened at Central Station The Hague. In both countries, the provided services are not part of the mandatory health insurance system, and patients have to pay for $\mathrm{OOH}$ visits.

45. Compared to most other OECD countries, retail clinics are widely developed across the United States. In the past decade, the number of medical clinics within retail stores rose from 818 clinics in 36 States in 2007 to 1260 clinics in 42 States in 2010. Almost $70 \%$ of patients using these clinics report that the primary purpose of their most recent visit was the diagnosis and treatment of a new illness or symptom, $26 \%$ needed vaccinations and $21 \%$ needed prescription renewals. In a recent review, the RAND showed that the vast majority of retail clinics are located in metropolitan areas, especially those with lower poverty rates and higher median incomes. Only $12.5 \%$ were located in underserved areas. In 2010, around 5\% of American families reported ever using a retail clinic while 3\% reported doing so in the previous year. Although their use appears to increase over time, the development of retail clinics to provide $\mathrm{OOH}$ primary care is not a promoted policy by national authorities. First, it might be too expensive for patients to get accessible $\mathrm{OOH}$ primary care, and second it detracts from efforts to ensure care continuity across the health care sector.

46. An interesting feature in the United Kingdom is that $85 \%$ of pharmacies now have a private consultation area where patients can discuss issues with pharmacy staff. Although these community pharmacies cannot be a dominant mode for organising $\mathrm{OOH}$ primary care, they can complement existing $\mathrm{OOH}$ primary care services through extended opening hours and pharmaceutical services for minor health conditions.

47. Few studies have assessed the impact of retail clinics. Mehrotra et al. (2009) found no significant difference in care quality between retail clinics, general practices, and urgent care centres. There is no apparent adverse impact on quality of care or delivery of preventive care, while they provide less costly treatment for three common illnesses (otitis, pharyngitis and urinary tract infection). In a similar vein, Patwardhan et al. (2012) showed that in the absence of retail clinics, $4.5 \%$ of $\mathrm{OOH}$ patients would have gone to the ED, $29.4 \%$ to UCCs and $56 \%$ would have consulted a PCP.

48. Although retail clinics provide cost-effective $\mathrm{OOH}$ primary care in the United States, such models only complement other OOH primary care services. One obvious reason is the risk that out-ofpocket payments related to retail clinic visits place too much of a financial burden on individuals, which discourages patients from seeking necessary care. 


\section{POLICIES TO IMPROVE ACCESS TO AND QUALITY OF OUT-OF-HOURS PRIMARY CARE}

49. OECD countries have adopted a range of policy levers to address challenges related to providing $\mathrm{OOH}$ primary care services. The policy survey documents two types of interventions to improve access to and quality of $\mathrm{OOH}$ primary care. The first consists of using existing resources in new ways. This includes providing better organisational and financial support to PCPs; using other health care professionals such as nurse practitioners, physician assistants and paramedics; and making $\mathrm{OOH}$ care participation compulsory for PCPs.

50. The second relates to the development of new infrastructure. This includes setting up a telephone triage system or advice line; using new technologies; as well as developing rich information systems underpinning $\mathrm{OOH}$ primary care.

Table 3. Policy levers to improve access and quality of $\mathrm{OOH}$ primary care

\begin{tabular}{|c|c|c|c|c|c|c|}
\hline Country & Participation & $\begin{array}{l}\text { Financial } \\
\text { incentives }\end{array}$ & $\begin{array}{l}\text { Telephone } \\
\text { triage or } \\
\text { advice or } \\
\text { website }\end{array}$ & $\begin{array}{l}\text { Use of other } \\
\text { health } \\
\text { professionals } \\
\#\end{array}$ & $\begin{array}{l}\text { Organisationa } \\
\text { I support }\end{array}$ & $\begin{array}{l}\text { Information } \\
\text { sharing }\end{array}$ \\
\hline Australia & Voluntary & Yes & Yes & Yes & Yes & Yes \\
\hline Austria & Compulsory & Yes & $\mathrm{No}^{*}$ & No & Yes & NR \\
\hline Belgium & Compulsory & Yes & Yes & Yes & Yes & Yes \\
\hline Canada & Compulsory** & Yes & Yes & Yes & Yes & Yes \\
\hline Chile & NR & Yes & Yes & Yes & No & NR \\
\hline Czech Rep. & Compulsory & Yes & Yes & No & Yes & Yes \\
\hline Denmark & Compulsory & Yes & Yes & No & Yes & Yes \\
\hline Estonia & Voluntary & Yes & No & No & No & Yes \\
\hline Finland & Compulsory & Yes & Yes & Yes & No & No \\
\hline France & Voluntary & Yes & Yes & No & Yes & NR \\
\hline Germany & Compulsory & Yes & Yes & Yes & No & NR \\
\hline Greece & Voluntary & Yes & No & Yes & No & No \\
\hline Hungary & Compulsory & NR & Yes & No & No & NR \\
\hline Iceland & Compulsory*** & Yes & Yes & No & No & Yes \\
\hline Israel & Voluntary & No & Yes & No & No & Yes \\
\hline Luxembourg & Compulsory & Yes & Yes & No & Yes & No \\
\hline Mexico & Voluntary & Yes & No & No & NR & No \\
\hline Netherlands & Compulsory & Yes & Yes & Yes & NR & NR \\
\hline Norway & Compulsory & Yes & Yes & No & Yes & Yes \\
\hline Poland & Voluntary & Yes & Yes & No & Yes & Yes \\
\hline Slovak Rep. & Compulsory & NR & No & No & NR & Yes \\
\hline Slovenia & Compulsory & Yes & Yes & No & No & NR \\
\hline Spain & Compulsory & No & Yes & No & No & Yes \\
\hline Switzerland $^{\star \star \star \star}$ & Compulsory & Yes & Yes & Yes & No & Yes \\
\hline Turkey & Compulsory & Yes & No & No & No & Yes \\
\hline UK & Voluntary & Yes & Yes & Yes & No & NR \\
\hline US & NR & Yes ${ }^{\star \star \star \star \star}$ & Yes & Yes & Yes & NR \\
\hline Total & 17 compulsory & 23 yes & 21 yes & 11 yes & 11 yes & 14 yes \\
\hline
\end{tabular}

Notes: NR means non-response. ${ }^{\#}$ Other health professionals include paramedics, nurse practitioners and physician assistants. ${ }^{*}$ In

Austria, a national telephone triage is under construction. ${ }^{* *}$ In Canada, participation is compulsory in some circumstances. ${ }^{* * *}$ In

Iceland, participation is compulsory in some cases, such as in rural areas. ${ }^{* \star *}$ In Switzerland, OOH primary care is generally delivered by physicians. Paramedics may carry out minor treatments, but do not work on their own in the $\mathrm{OOH}$ setting. Participation for PCPs is in principle compulsory, but cantons can define exceptional criteria. ${ }^{* * \star * \star}$ In the US, additional compensation is provided for PCPs in some places.

Source: OECD Policy Survey on the delivery of out-of-hours primary care services (2015). 


\subsection{Using existing resources in new ways}

51. Interventions pursued, which use existing resources in new ways, are diverse and range from providing organisational support to PCPs (such as free space in facilities, administrative support and health care resources), rewarding PCPs with adequate financial compensation, using Emergency Care Practitioners or other paramedics to deliver basic emergency care, to making PCP participation compulsory. Providing financial compensation is the most common solution adopted by OECD countries, perhaps because the latter is the softer way to improve PCP participation in $\mathrm{OOH}$ primary care. By contrast, $\mathrm{PCP}$ participation in $\mathrm{OOH}$ care is compulsory in 17 OECD countries. This is the most forceful way to provide patients with appropriate access to $\mathrm{OOH}$ care.

\section{Providing organisational support can improve working conditions and make out-of-hours work more appealing}

52. A few OECD countries have started to actively support the development of OOH primary care through the provision of non-financial resources such as organisational support. The overarching objective is to improve the quality of working life and to make $\mathrm{OOH}$ activity more attractive, notably by reducing administrative burden and minimising personal investment. Among the 27 OECD countries participating in the survey, 11 (Australia, Austria, Belgium, Canada, Czech Republic, Denmark, France, Luxembourg, Norway, Poland, and the United States) report providing organisational support to encourage the participation of PCPs to deliver OOH primary care (Table 3).

53. Three types of organisational supports are reported in the policy survey. The most common approach, seen in Austria, the Czech Republic, Denmark, France, Norway and Poland, is to provide free space in facilities. Other countries, such as Belgium, Czech Republic and Luxembourg, report providing administrative and technical resources to PCPs. In Belgium and Luxembourg, for example, the Government funds administrative staff. In the Czech Republic, regional authorities provide medical offices with all necessary materials and instruments. In Norway, some municipalities offer free space in facilities, medical offices with materials and instruments, and health secretaries. The last approach is to provide PCPs with extra health care resources. In Canada, for example, physicians practising within primary care teams benefit from extra health care resources such as nurses.

54. Providing organisational support such as free space in facilities, administrative and health care resources are worth considering as options to actively support the development of $\mathrm{OOH}$ primary care across OECD countries. Efforts in this direction can be scaled up in order to make progress toward the goal of improving access to $\mathrm{OOH}$ primary care. In particular, supporting a wider use of information and communications technology (ICT) to facilitate communication and information sharing between regular $\mathrm{PCP}$ and $\mathrm{OOH}$ arrangements is essential, as emphasised in Section 3.2.

\section{Rewarding primary care physicians may make their participation in out-of-hours care more appealing}

55. Almost all OECD countries (23 out of 27 countries that responded to the policy survey) provide additional financial compensation to PCPs for providing $\mathrm{OOH}$ care, although in some countries this may not be applied consistently. Whilst the current trend is to compensate PCPs because OOH care is considered overtime and may also imply extra responsibilities, there is diversity in the current approaches. Some OECD countries provide a higher fee to compensate for $\mathrm{OOH}$ services through, for example, a lump sum payment. Other countries adopt a more sophisticated approach, with fee adjustment depending on the period of time, the number of consultations given and the geographical area in which they practise.

56. In the United Kingdom, for example, GPs that opt in to $\mathrm{OOH}$ care receive more funding than others, typically equivalent to $6 \%$ of their total budget (around GBP 4 per registered patient). By contrast, 
$\mathrm{OOH}$ compensation in Luxembourg is paid according to the $\mathrm{OOH}$ time range. From $8 \mathrm{pm}$ to $12 \mathrm{pm}$, physicians are paid EUR 26.271 per duty range of four hours at a time; from $12 \mathrm{pm}$ to 7 am they are paid EUR 91.948 per duty range of seven hours at a time, and from 8 am to 12pm they are paid EUR 52.542 per duty range of eight hours at a time. In Canada, in cases where participation is voluntary, PCPs are offered financial incentives equivalent to $40 \%$ to $60 \%$ of the fee charged to the Ministry of Health, while they can receive up to $20 \%$ of the fee for their $\mathrm{OOH}$ availability in cases where participation is compulsory (e.g., for those working in primary care teams). In Norway, the ordinary remuneration of PCPs in the fee-for-service system is higher $\mathrm{OOH}$ than during in-hours. PCPs also receive funding from the municipality. There are also initiatives to stimulate recruitment and stability in general medical services where municipalities with these challenges receive extra funding through grants. Interestingly, in the Slovak Republic, $\mathrm{OOH}$ participation is compulsory and absence from duty entails a financial penalty.

57. One of the most sophisticated schemes is perhaps the Australian Practice Incentives Programme (PIP) After-Hours Incentive, which was re-established in July 2015. The after-hours period is broken down into: (i) sociable after-hours period from $6 \mathrm{pm}$ to $11 \mathrm{pm}$ weeknights; and (ii) unsociable after-hours period from $11 \mathrm{pm}$ to $8 \mathrm{am}$ weekdays, hours outside of 8am and 12pm Saturdays, and all day Sunday and public holidays. There are five payment levels for which accredited general practices can apply (Box 3). The payment levels go from AUS 1 to AUS 11 per Standardised Whole Patient Equivalent ${ }^{2}$ (SPWE). Practices can qualify for only one payment level and the levels are not cumulative. Payment levels cater to a range of geographical and organisational differences. Participating practices located outside capital cities and major metropolitan centres are paid a rural loading in recognition of the difficulties of providing care, often with little professional support, in rural and remote areas.

\section{Box 3. The PIP After-Hours Incentives Programme in Australia}

The PIP After-Hours Incentive is a nationally-consistent model that aims to encourage practices to provide $\mathrm{OOH}$ services to their patients. It builds on existing infrastructure and provides general practices with a less administratively burdensome way to receive funding for delivering $\mathrm{OOH}$ services. The five payment levels are:

- $\quad$ Level 1 Participation Payment: \$1 per Standardised Whole Patient Equivalent (SWPE)

Practices must have formal arrangements in place to ensure that practice patients have access to care in the complete after-hours period (hours outside of $8 \mathrm{am}$ to $6 \mathrm{pm}$ weeknights; hours outside of $8 \mathrm{am}$ to $12 \mathrm{pm}$ Saturdays; and all day Sundays and public holidays).

\section{- $\quad$ Level 2 Sociable After-Hours Cooperative Coverage Payment: \$4 per SWPE}

Practices must participate in a cooperative arrangement with other general practices that provide afterhours care to practice patients in the sociable after-hours period (6pm to $11 \mathrm{pm}$ weeknights), and ensure formal arrangements are in place to cover the unsociable after-hours period (11pm to 8am weekdays, hours outside of $8 \mathrm{am}$ and 12pm Saturdays and all day Sundays and public holidays).

- $\quad$ Level 3 Sociable After-Hours Practice Coverage Payment: $\$ 5.50$ per SWPE

Practices must provide after-hours care to practice patients directly through the practice in the sociable after-hours period $(6 \mathrm{pm}$ to $11 \mathrm{pm}$ weeknights); and ensure formal arrangements are in place to cover the unsociable after-hours period (11pm to 8am weekdays, hours outside of 8am and 12pm Saturdays and all day Sundays and public holidays).

2. (SWPE) is a measure of practice size and includes a weighting factor for the age and gender of patients. 


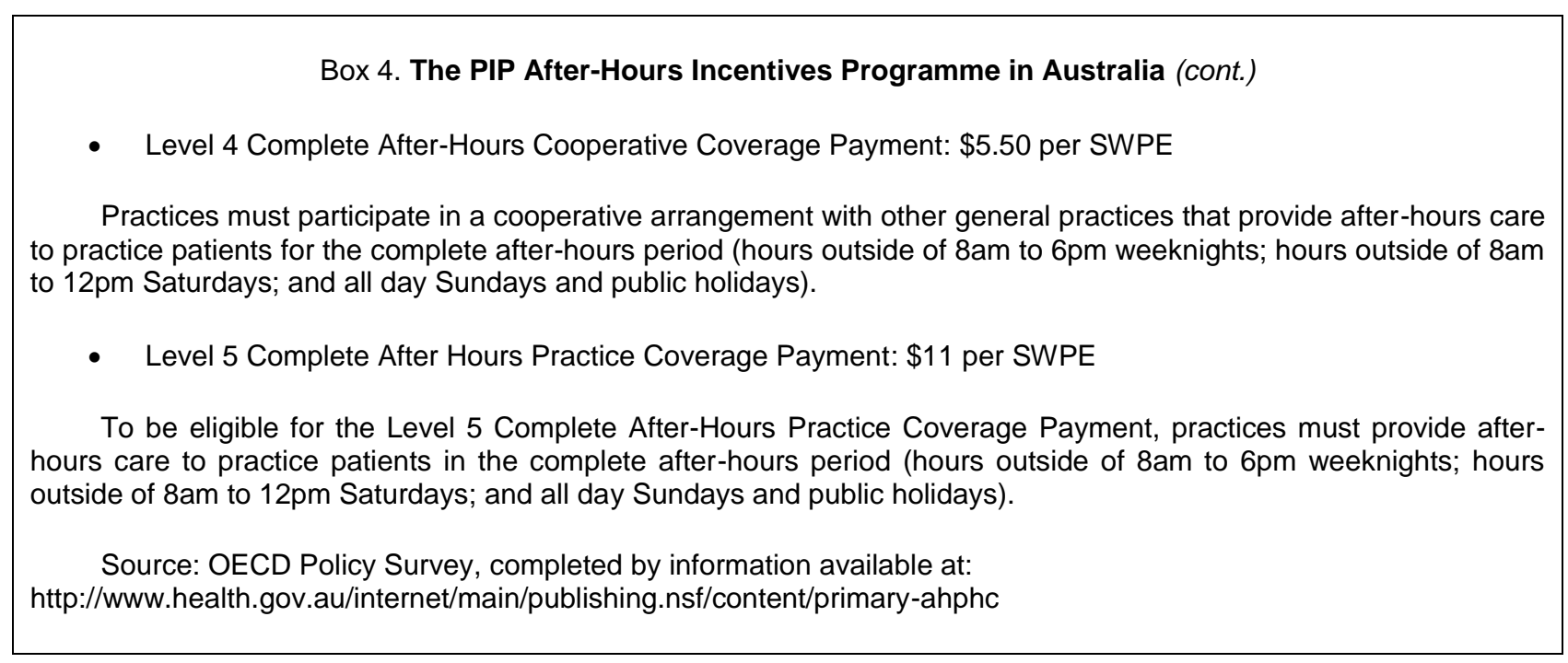

58. The use of financial incentives should not be considered as a complete solution to increase participation. A recent study used Australian GP survey data to model the probability of GPs providing $\mathrm{OOH}$ care. It suggests that an increase in $\mathrm{OOH}$ care hourly earnings increases the probability of providing $\mathrm{OOH}$ care for both male and female doctors, but the magnitude appears to be small. The positive effect is stronger among GPs in rural areas, but still small (Broadway et al, 2016). Although financial compensation is important to recognise PCPs that provide primary care 24 hours a day, seven days a week, such policies need to be balanced with other policy levers to provide support to PCPs and maximise their participation in $\mathrm{OOH}$ care, and patients' access to services.

\section{Other health professionals, such as paramedics and nurse practitioners, can help tackle workforce shortages and deliver more accessible out-of-hours care, particularly in rural and remote areas}

59. Changing scopes of practice, including assessment, triage, and treatment skills for different health professionals such as nurse practitioners and paramedics, is widely recommended to help manage the increasing demands for health care and also to tackle geographical variations in access to care (NACHC, 2013; NGA, 2012; Naylor and Kurtzan, 2010). Given the provision of OOH care is challenging, particularly due to a lack of health care resources and workforce shortages in some rural and remote areas, it is becoming critical to change scopes of practice and to use other health professionals to provide $\mathrm{OOH}$ primary care services. A positive trend that is apparent in some OECD countries is the growing role of nurse practitioners, physician assistants or emergency care practitioners to carry out assessments and treatments traditionally carried out only by doctors. With appropriate training, other health care workers can provide clinically effective $\mathrm{OOH}$ primary care. This is a powerful way to increase $\mathrm{OOH}$ primary care capacity.

60. However, non-medical health professionals appear to be under-used in the provision of $\mathrm{OOH}$ primary care in OECD countries. Only 11 OECD countries (Australia, Belgium, Canada, Chile, Finland, Germany, Greece, Netherlands, Switzerland, United Kingdom and United States) use other health professionals such as nurse practitioners, paramedics and physician assistants to deliver OOH primary care to some extent (Table 3). The most extensive approach is seen in England and the United States.

61. In England, Emergency Care Practitioners (ECPs) are paramedics who have undertaken additional training to assess, treat and refer patients to the most appropriate medical services. Interestingly, they can work with PCPs in $\mathrm{OOH}$ primary care services. If a home visit is deemed necessary, the PCP decides if the patient's condition is suitable for an ECP, or whether a PCP is required (Halter et al, 2007; Mason et al, 2007). In Australia there have been similar initiatives enabling Extended Care Paramedics to 
treat low-acuity patients in some states (South Australia, New South Wales, and the Australian Capital Territory). In the United States, nurse practitioners and physician assistants are also widely used for the provision of $\mathrm{OOH}$ primary care. The Agency for Healthcare Research and Quality (AHRQ, 2012) estimates that around $52 \%$ of nurse practitioners and $43 \%$ of physician assistants were providing primary care in the United States in 2010, both during usual hours and OOH.

62. A new model of community has also been developed in a number of states. Community paramedics are trained to perform patient assessments and to provide care in home and community settings under $\mathrm{OOH}$ care. The overarching aim is to facilitate more appropriate use of emergency care resources and to enhance access to primary care 24/7 for medically underserved populations. In other countries, including Canada, Chile, Germany, Greece, the Netherlands, Slovenia and Switzerland, nurse practitioners and physician assistants are also used to complement (and sometimes substitute) medical services for $\mathrm{OOH}$ care. In Switzerland, $\mathrm{OOH}$ primary care is generally delivered by physicians. Paramedics may carry out minor treatment but do not work on their own in the OOH setting.

63. The body of evidence suggesting that the use of other health care workers can make a positive contribution in providing $\mathrm{OOH}$ care is conclusive. In England, a randomised controlled trial found paramedics with extended skills can provide effective response compared to standard ambulance transfer and treatment in an ED for elderly patients with acute minor conditions (Mason et al, 2007). Overall, patients attended by a paramedic practitioner were less likely to visit hospital EDs and to undergo some form of investigation. Care provided by paramedic practitioners reduces the need for subsequent referral to unscheduled care services in a large proportion of cases, and leads to greater patient satisfaction. In another study conducted in England, results were similar, supporting the safety of practice for ECPs (Halter et al, 2007). Overall, 86.4\% of patients reported that the ECP had been clear about their assessment, but only $58 \%$ reported that their health was now "better". Most patients treated at home by the practitioners appeared satisfied and compliant with the care provided (Halter et al, 2007). In a systematic review of the literature examining the activity and impact of ECPs in the NHS, Hill et al. (2014) show greater overall patient satisfaction and better processes of care compared with control practitioners. In some case, the authors find cost savings associated with the use of ECPs. There is evidence in Australia that paramedics are playing a growing role, especially in small rural communities (O'Meara et al, 2002). They are becoming first-line primary health care providers and have the capacity to facilitate a higher quality of emergency health system for communities in remote areas. It is compulsory for primary care physicians to participate in the provision of out-of-hours care in half
of OECD countries

64. Making $\mathrm{OOH}$ care participation compulsory for PCPs is the most forceful policy tool to increase $\mathrm{OOH}$ care accessibility. The policy survey indicates that 17 OECD countries make PCP participation compulsory in the provision of $\mathrm{OOH}$ primary care (Austria, Belgium, Canada, Czech Republic, Denmark, Finland, Germany, Hungary, Iceland, Luxembourg, the Netherlands, Norway, Slovak Republic, Slovenia, Spain, Switzerland and Turkey). Participation is voluntary in eight OECD countries: Australia, Estonia, France, Greece, Israel, Mexico, Poland, and the United Kingdom.

65. Although coercive, making $\mathrm{OOH}$ primary care participation compulsory for PCPs is the most effective way to ensure patients have greater access. By increasing the number of PCPs involved in the provision of $\mathrm{OOH}$ care, this policy lever also has potential to reduce physician workload and burden. Compulsory participation is enforced in OECD countries in different ways. This includes making it a condition of registration to practise; making it a requirement to meet accreditation standards; making it a condition in contracts; or financially penalising those who do not participate. 


\subsection{Developing new infrastructure}

66. Interventions that have been pursued to improve access to and quality of $\mathrm{OOH}$ primary care through the development of new infrastructure entail setting up telephone triage and the development of new technologies (including websites, apps or tele-consultation), as well as the strengthening of the health information systems underpinning $\mathrm{OOH}$ primary care. While the former is more common in OECD countries, the latter is required to strive for improvement in access and care quality, notably through greater care continuity and co-ordination.

\section{A telephone triage line or helpline and the use of other health technologies have the potential to relieve pressure on primary care physicians and to improve access to appropriate out-of-hours services}

67. Telephone triage lines or help lines, or the use of other health technologies (such as websitebased services), can either be part of an $\mathrm{OOH}$ primary care service or a separate model to act as an intermediary between patients and the $\mathrm{OOH}$ model. In both cases, they are pathways to access to primary and urgent care, especially during $\mathrm{OOH}$. By providing medical advice and directing patients to the most appropriate $\mathrm{OOH}$ services, telephone triage lines or website-based services are used as a tool to (i) reduce PCP workload; (ii) decrease inappropriate ED visits and; (iii) support timely access to $\mathrm{OOH}$ primary care by tackling geographical barriers. Telephone triage or advice services have been developed in 21 OECD countries (Table 3 ).

68. Denmark's telephone-based service is unique in OECD countries. The OOH primary care service is organised in GPCs, covering between 0.6 and 1.8 million inhabitants. Calling the $\mathrm{OOH}$ service via one single telephone number per region is compulsory before a face-to-face consultation. Since 2014, the telephone-based service is the only entry point into the system for patients who are injured or experience sudden illness outside normal office hours. Calls are answered and triaged by PCPs, who either complete the call as a telephone consultation or refer the patient to a GPC for a consultation or home visit. The system in each region relies on one PCP on duty for the $\mathrm{OOH}$ telephone-based triage and at least two PCPs on $\mathrm{OOH}$ duty to make face-to-face consultations. PCPs, on the basis of telephone consultation, can prescribe medication and schedule a follow-up visit at the clinic or at home (Moth et al, 2014). A relatively large share of calls $(60 \%)$ to the Danish $\mathrm{OOH}$ primary care is terminated on the telephone through the provision of medical advice and prescription of medication (Moth et al, 2014).

69. Patients in the Netherlands are required to call the "HAP" ("Huisartsen praktijk") to get medical advice. As mentioned in Section 2, nurses perform telephone triage under the supervision of PCPs. Patients are directed to the most appropriate services. Depending on the medical condition, the HAP advises the patient to (i) stay at home and visit a PCP during normal working hours; (ii) go to the HAP; or (iii) go directly to the hospital ED or call an ambulance. The literature on the safety and effectiveness of telephone triage is mixed. Some studies suggest that it can lead to inappropriate triage, with concern that the level of urgency is under-estimated (Derkx et al, 2008; Giesen et al, 2007a). Studies have also pointed to a low degree of patient satisfaction, although this can be linked to patients' expectations not being met (Giesen et al, 2007b). However, Giesen et al (2007a) also found a significant positive relationship between the accurate estimation of urgency and specific training on telephone guidelines, suggesting training can help improve effectiveness of care.

70. In Australia, a new after-hours general practitioner advice and support line was introduced on July 2015. The new service provides access to medical advice and support for patients in all geographical areas (metropolitan, rural and remote areas) who do not have access to face-to-face primary care services during out-of-hours. A registered nurse completes an assessment of the health issue and based on symptoms, the nurse may offer a call back from a PCP. Depending on the severity and urgency of the health condition, the PCP will contact the patient within 15 minutes or 1 hour. 
71. Much of the evidence, however, suggests that telephone triage is safe, and can even reduce PCP workload. A Cochrane systematic review of nine studies found telephone consultations appeared to be as safe as face-to-face consultations. There was no evidence of an increase in adverse effects. Telephone triage reduced immediate PCP or home visits and, in general, at least $50 \%$ of calls could be handled by telephone advice alone (Bunn et al, 2004). A randomised controlled trial in a GPC in England found nurse telephone consultations that use decision support software to assist were safe and effective, and compared with the GPC alone there was no increase in the number of adverse events including deaths, or the number of attendances at an ED within three days after a call (Lattimer et al, 1998). In Australia, an audit of the Nurse-on-Call telephone line concluded it was overall safe and cost-effective, although there was scope to improve the quality of advice given. Total reported incidents were extremely low at 105 out of 1.47 million calls, although $4 \%$ of calls reviewed through mystery caller testing did not meet clinical safety standards (Victorian Auditor-General, 2010).

72. Beyond telephone triage, there are also websites (www.thuisarts.nl "physician at home") and apps for smartphones (www.moetiknaardedokter.nl "Should I go to the physician") in the Netherlands. The overarching objective is to help people in deciding whether to go to a physician and how urgent their complaint is. These applications can be accessed at any time, and might help direct patients to the most appropriate $\mathrm{OOH}$ services, which can reduce both physician workload and inappropriate ED visits. So far, there is no evidence on their impact.

73. Since April 2013 in the United Kingdom, the usual route for people to access OOH primary care services is to call NHS 111. The NHS 111 was developed to improve access to urgent care, increase efficiency by directing patients to the appropriate place of treatment, increase patient satisfaction and reduce the longer-term unnecessary use of EDs. The NHS 111 service is staffed by a team of fully trained advisers, supported by experienced nurses and paramedics. A clinical assessment tool called NHS Pathways is used to get information about the caller's symptoms and direct them to the appropriate service. Four cases are assessed including emergencies (either calling an ambulance or sending the patient to an ED department); requiring urgent primary care; or as more routine, giving advice or telling the caller to contact their in-hours GP. When NHS 111 assesses that a person needs primary care, the medical team:

- arranges for a clinician from the OOH GP service to call the patient back and conduct a further clinical assessment;

- books the patient an appointment at the nearest $\mathrm{OOH}$ clinic (urgent care centre, walk-in centre, etc.); or

- arranges for an $\mathrm{OOH}$ GP to visit the patient at home.

74. Patient satisfaction with NHS 111 is very good, with $73 \%$ of respondents reporting they were satisfied and 19\% quite satisfied with the service (Turner, 2012). The National Audit Office (2014) found NHS 111 led to a reduction in the number of cases being handled by OOH PCP services. However, a before and after controlled evaluation of NHS 111 found in its first year, there was no change overall in emergency ambulance calls, emergency department attendances or urgent care use (Turner, 2013).

75. Another interesting initiative is seen in Switzerland. The company Medgate ${ }^{3}$ has developed a telemedicine centre to provide patients with medical advice at all hours, including nights and weekends. The medical team is reachable by phone, email or a video link that allows for teleconsultations. In one example of how it can be used, a patient can take photos of affected skin sites and send them by email or by using the Medgate app. The medical team will respond with the necessary treatment plan, which may

3. Information available at http://www.medgate.ch/en-us/telemedicinecenter.aspx 
include a prescription. The video link option is possible in 200 pharmacies in the country. The pharmacist makes the initial patient assessment and is then joined by a physician with the use of a video system. The physician may issue a prescription or refer the patient to the appropriate medical services. The Medgate example is not yet a common form of $\mathrm{OOH}$ primary care delivery in Switzerland. Such websites and other technologies allowing patients to more easily access health professionals are a very promising way to improve access and relieve pressure on PCPs. They could therefore be trialled in other OECD countries. As there is no evidence on their impact, policy makers need to be sure such innovations offer value for their health systems by conducting thorough evaluations.

\section{Developing health information infrastructure underpinning out-of-hours primary care services is essential to improve access and care quality}

76. An essential policy lever to ensure that $\mathrm{OOH}$ primary care is accessible and effective is to collect information around $\mathrm{OOH}$ care. Collecting and analysing data underpinning $\mathrm{OOH}$ primary care is a key element to build a fuller and more detailed picture of the effectiveness, safety and patient-centredness of $\mathrm{OOH}$ primary care. Current approaches in OECD countries are, however, often inadequate due to a lack of data availability around $\mathrm{OOH}$ primary care.

77. In most OECD countries there is a critical need to develop robust information systems to collect a comprehensive number of indicators on both the activities and outcomes delivered during $\mathrm{OOH}$ primary care. Candidate indicators to measure access and quality of $\mathrm{OOH}$ care would most likely concentrate on the timeliness of the $\mathrm{OOH}$ responses, the co-ordination between $\mathrm{OOH}$ providers and regular PCPs, and around patient experience with $\mathrm{OOH}$ care. Scotland is an interesting example that could guide other OECD countries. Healthcare Improvement Scotland has developed quality indicators for $\mathrm{OOH}$ primary care (Box 4). These indicators apply to all territorial NHS Boards in Scotland, NHS 24, and all OOH primary care services either provided directly by, or secured on behalf of, NHS Boards. The indicators are intended to identify good practice and potential problems, so that NHS Boards may be benchmarked against their peers. The indicators are accompanied by standards for the provision of $\mathrm{OOH}$ primary care. All providers are required to complete an annual review of quality indicators and develop improvement plans. Currently, little of this information is made publicly available, although Scotland's Public Health and Intelligence services are undertaking work to create an Out of Hours Data set to inform policy development and to provide some limited publicly accessible information (OECD, 2016). A nationally consistent approach to data collection has been developed, including automated data collected via "Adastra", the OOH patient management system used in all 14 territorial NHS boards, and manual data collection methods (Healthcare Improvement Scotland, 2014). This is a valuable initiative that other countries should consider. 
Box 5. Quality indicators for out-of-hours primary care services in Scotland

\section{Indicator 1: Response times:}

- Proportion of calls to NHS 24 answered within 30 seconds by an NHS 24 call handler.

- Proportion of home visit cases where a clinician arrives at the destination of care within the timescale recommended by triage.

- Volume and proportion of 1, 2 and 4-hour home visit referrals.

Indicator 2: Appropriateness of triage for home visits:

- Proportion of clinically appropriate 1, 2 and 4-hour home visit referrals.

\section{Indicator 3: Effective information exchange:}

- Proportion of primary care out-of-hours consultations during which the patient's electronic care summary is accessed by a clinician.

- Proportion of primary care out-of-hours consultations with patients registered with a GP within the same NHS board for which consultation information is provided to their GP by 8.30 am the following working day.

- Proportion of primary care out-of-hours consultations resulting in admission to acute care for which referral information is provided at the time of referral.

\section{Indicator 4: Implementing national clinical standards and guidelines:}

- Proportion of patients with a suspected or confirmed diagnosis of asthma assessed in line with current national standards and guidelines.

\section{Indicator 5: Antimicrobial prescribing:}

- Proportion of prescriptions of antimicrobial medications that are for high-risk antimicrobial medications (cephalosporins, quinolones, co-amoxiclav and clindamycin).

\section{Indicator 6: Patient experience:}

- Proportion of primary care out-of-hours service patients who report a positive experience.

- Proportion of primary care out-of-hours service patients who say they got the outcome (or care/support) they expected and needed.

- Proportion of complaints received from primary care out-of-hours service patients.

Source: Healthcare Improvement Scotland (2014), Quality Indicators for Primary Care Out-of-Hours Services, NHS Scotland. 
78. At the same time, OECD countries should ensure information sharing between OOH providers and the patient's usual PCP. Yet this is not the norm across OECD countries. Of significant concern, most countries participating in the policy survey do not have strategies to ensure information sharing and guarantee care continuity. Only 14 countries (Australia, Belgium, Canada, the Czech Republic, Denmark, Estonia, Iceland, Israel, Poland, Slovak Republic, Spain and Turkey) have some kind of system in place to facilitate information exchange between $\mathrm{OOH}$ services and regular PCPs (Table 3), although this is not systematic in all those countries.

79. Approaches undertaken in Belgium, Denmark, Estonia, Iceland, Israel, Poland, Spain and Turkey appear more sophisticated, with the use of electronic health records to foster care continuity between normal hours and $\mathrm{OOH}$ care. Norway has an aim that regular PCPs shall be notified when their patients visit the OOH EPCC, but this is yet not the case nationally. When patients attend the EPCC, the patient is asked for their regular PCP's name. However, only in smaller municipalities and in a few larger ones are the PCPs notified. As a result, the degree of continuity between normal hours and $\mathrm{OOH}$ care varies. Switzerland is developing its health information system with the project MARS (Modules Ambulatoires des Relevés sur la santé), particularly in primary care services. The parliament adopted a new law setting the legal framework for the introduction of electronic patient files. While this includes OOH primary care services, participation for providers and patients is voluntary. 


\section{CONCLUSIONS}

80. The provision of $\mathrm{OOH}$ primary care services is a complex policy issue for OECD countries. The 27 OECD countries participating in the policy survey have adopted several models of OOH primary care services. Seven main models of $\mathrm{OOH}$ primary care exist alongside one another: practice-based services, rota groups, deputising services, hospital EDs, PCCs, GPCs and retails clinics. Hospital EDs, rota groups and practice-based services remain the most common $\mathrm{OOH}$ arrangements, but there is a tendency to shift $\mathrm{OOH}$ primary care toward large-scale organisations such as GPCs and to establish PCC facilities. Hospital EDs to some extent are more likely to manage primary care patients $\mathrm{OOH}$ in countries that rely on practice-based services and rota groups for the provision of $\mathrm{OOH}$ primary care. Deputising services and retail clinics are more modestly developed in OECD countries.

81. Primary care is expected to be patient-centred and respond to the needs of patients 24 hours a day, seven days a week. However, as outlined in the policy survey, most often primary care doctor offices close between 5pm and 8am; and due to lack of financial and human resources, health systems are struggling to ensure comprehensive provision of primary care services. Health systems often react to $\mathrm{OOH}$ challenges with short-term tactical responses rather than a coherent long-term strategy. Although valuable initiatives have recently been implemented, an essential element rarely considered when organising $\mathrm{OOH}$ primary care is to ensure co-ordination and informational continuity between regular PCPs and OOH primary care. A sophisticated system, with automatic information sharing between a patient's regular PCP and $\mathrm{OOH}$ arrangement would be essential for the effectiveness and safety of care.

82. Beyond this, the following recommendations can be drawn to improve access to and quality of $\mathrm{OOH}$ primary care services across OECD countries:

- The GPC is an effective model for organising $\mathrm{OOH}$ primary care, providing safe and accessible care. Patients report high satisfaction, PCP workload is reduced and health care costs are likely to be reduced by diverting primary care patients from EDs to GPCs. There is strong evidence that integrating these facilities with hospital EDs reduces self-referrals to hospital EDs.

- Monitoring quality and outcomes achieved within OOH primary care is critical to ensure that care is accessible and effective. The approach developed by Scotland could guide other OECD countries to build a more detailed picture of the effectiveness, safety and patient-centeredness of $\mathrm{OOH}$ primary care. In several health systems, there is scope to collect quality indicators around the timeliness of the $\mathrm{OOH}$ responses, the co-ordination between $\mathrm{OOH}$ providers and regular $\mathrm{PCPs}$, or around patient experience with $\mathrm{OOH}$ primary care.

- Considering compulsory participation in the provision of $\mathrm{OOH}$ care for PCPs, while providing adequate financial and organisational supports, are effective ways to tackle PCPs' reluctance to practise. Such solutions make $\mathrm{OOH}$ activities more appealing and might also minimise the burden for PCPs, while improving their quality of working life. 
- Telephone triage is a valuable policy tool to improve awareness of service availability, reduce patient confusion and improve access to $\mathrm{OOH}$ care in more remote areas. A national telephone triage line, as seen in the Netherlands and Denmark, can act as the entry point of all $\mathrm{OOH}$ primary care services to direct patients to the most appropriate service, making the system less complicated for patients.

- The use of other health care professionals is particularly relevant to improve access to $\mathrm{OOH}$ primary care, notably in rural settings with limited health care resources and long travel distances. Notably, nurse practitioners, physician assistants, paramedics and emergency care practitioners have been found to deliver care that is comparable to PCPs on several process and outcome measures, and also provide improved access to care for sparsely-populated areas. 


\section{REFERENCES}

AHRQ - Agency for Healthcare Quality and Research (2012), Primary Care Workforce Facts and Stats No. 3: Distribution of the U.S. Primary Care Workforce, AHRQ Pub. No.12-P001-4-EF, http://www.ahrq.gov/sites/default/files/publications/files/pcwork3.pdf.

Berchet, C. (2015), "Emergency Care Services: Trends, Drivers and Interventions to Manage the Demand", OECD Health Working Papers, No. 83, OECD Publishing, Paris. http://dx.doi.org/10.1787/5jrts344crns-en

Britt, H., et al. (2014), A Decade of Australian General Practice Activity 2004-05 to 2013-14, General practice series no. 37, Sydney University Press, Sydney.

Broadway, B., et al. (2016), Do Financial Incentives Influence GPs' Decisions to Do After-Hours Work? A Discrete Choice Labour Supply Model, Institute for the Study of Labor (IZA), Discussion Paper No. 9910, Bonn.

Buja, A., et al. (2015), "Out-of-hours primary care services: Demands and patient referral patterns in a Veneto region (Italy) Local Health Authority”, Health Policy, Vol. 119, No. 4, pp. 437-446. doi:10.1016/j.healthpol.2015.01.001

Bunn, F., G. Byrne and S. Kendall (2004), "Telephone consultation and triage: effects on health care use and patient satisfaction (review)", Cochrane Database of Systematic Reviews, Oct 18;(4):CD004180.

Campbell, N.C., et al. (2006), "A qualitative study in rural and urban areas on whether - and how - to consult during routine and out of hours", BMC Family Practice, Apr 26;7:26. doi:10.1186/14712296-7-26

Christensen, M.B. and F. Olesen (1998), "Out of hours service in Denmark: evaluation five years after reform”, BMJ, Vol. 316, No. 7143, pp. 1502-1505. doi:10.1136/bmj.316.7143.1502

Cour des comptes (2013), Rapport sur l'application des lois de financement de la sécurité sociale pour 2013, chapitre XII: la permanence des soins, La Documentation française, septembre 2013, pp. 579585, available at: www.ccomptes.fr

Cour des comptes (2014). Rapport sur l'application des lois de financement de la sécurité sociale pour 2014, chapitre XII : Les urgences hospitalières : une fréquentation croissante, une articulation avec la médecine de ville à repenser. La Documentation française, septembre 2014, pp. 351-377, available at: www.ccomptes.fr

Cragg, D.K., et al. (1997), "Comparison of out of hours care provided by patients' own general practitioners and commercial deputising services: a randomised controlled trial. I: the process of care", BMJ, Vol. 314, No. 7075, pp. 187-189.

Den Boer-Woltersa, D. et al. (2010), "Frequent attendance of primary care out-of-hours services in The Netherlands: characteristics of patients and presented morbidity", Family Practice, Vol. 27, No. 2, pp. 129-134. doi:10.1093/fampra/cmp103 
Derkx, H.P., et al. (2008), "Quality of clinical aspects of call handling at Dutch out of hours centres: cross sectional national study", British Medical Journal, 12;337:a1264. doi:10.1136/bmj.a1264

Flarup, L., et al. (2014), "Chronic-disease patients and their use of out-of-hours primary health care: a cross-sectional study”, BMC Family Practice, 15:114. doi:10.1186/1471-2296-15-114

Fry, M.M. (2011), "A systematic review of the impact of afterhours care models on emergency departments, ambulance and general practice services", Australasian Emergency Nursing Journal, Vol. 14, No. 4, pp. 217-225. doi:10.1016/j.aenj.2011.09.001

Giesen, P., et al. (2007a), "Safety of telephone triage in general practitioner cooperatives: do triage nurses correctly estimate urgency?" Quality \& Safety in Health Care, Vol. 16, No. 3, pp. 181-184. doi:10.1136/qshc.2006.018846

Giesen, P., et al. (2007b), "Patients evaluate accessibility and nurse telephone consultations in out-of-hours GP care: Determinants of a negative evaluation", Patient Education \& Counseling, Vol. 65, No. 1, pp. 131-136. Patients evaluate accessibility and nurse telephone consultations in out-of-hours GP care: doi:10.1016/j.pec.2006.06.021

Grant, C. et al. (2002), "An observational study comparing quality of care in walk-in centres with general practice and NHS Direct using standardised patients", BMJ, 324(7353):1556.

Grol, R., P. Giesen and C. van Uden (2006), "After-hours care in the United Kingdom, Denmark, and the Netherlands: new models", Health Affairs, Vol. 25, No. 6, pp. 1733-1737. doi:10.1377/hlthaff.25.6.1733

Halter, M., et al. (2007), "A patient survey of out-of-hours care provided by Emergency Care Practitioners", BMC Emergency Medicine, 7:4. doi:10.1186/1471-227X-7-4

Hansen B.L. and A. Munck (1998), "Out-of-hours service in Denmark: the effect of a structural change", British Journal of General Practice, Vol. 48, No. 433, pp. 1497-1499.

Healthcare Improvement Scotland (2014), Quality Indicators for Primary Care Out-of-Hours Services, NHS Scotland.

Hill, H., P. McMeekin and C. Price (2014), "A systematic review of the activity and impact of emergency care practitioners in the NHS", Emergency Medicine Journal, Vol. 31, No. 10, pp. 853860. doi:10.1136/emermed-2013-202660

Huber, C.A., et al. (2011), "Out-of-hours demand in primary care: frequency, mode of contact and reasons for encounter in Switzerland", Journal of Evaluation in Clinical Practice, Vol. 17, No. 1, pp. 174179. doi:10.1111/j.1365-2753.2010.01418.x

Huibers, L., et al. (2009), "Out-of-hours care in western countries: assessment of different organizational models", BMC Health Services Research, 9:105. doi:10.1186/1472-6963-9-105

Huibers, L. et al. (2014), "EurOOHnet - the European research network for out-of-hours primary health care", European Journal of General Practice, Vol. 20, No. 3, pp. 229-232. doi: $10.3109 / 13814788.2013 .846320$

Hutchison, B. et al. (2003), "Patient satisfaction and quality of care in walk-in clinics, family practices and emergency departments: the Ontario Walk-In Clinic Study", CMAJ, Vol. 168, No. 8, pp. 977-983. 
Jerant, A., et al. (2012), "Extended office hours and health care expenditures: a national study", Annals of Family Medicine, Vol. 10, No. 5, pp. 388-395. doi:10.1370/afm.1382

Jones, P., B. Elangbam and N.R. Williams (2010), "Inappropriate use and interpretation of D-dimer testing in the emergency department: an unexpected adverse effect of meeting the "4-h target", Emergency Medicine Journal, Vol. 27, No. 1, pp. 43-47. doi:10.1136/emj.2009.075838

Kool R.B., D.J. Homberg and H.C.M. Kamphuis (2008), “Towards integration of general practitioner posts and accident and emergency departments: a case study of two integrated emergency posts in the Netherlands", BMC Health Services Research, 8:225. doi:10.1186/1472-6963-8-225

Lattimer, V., et al. (1998), "Safety and effectiveness of nurse telephone consultation in out of hours primary care: randomised controlled trial”, BMJ, Vol. 317, No. 7165, pp. 1054-1059. doi:10.1136/bmj.317.7165.1054

Leibowitz, R., S. Day and D. Dunt (2003), “A systematic review of the effect of different models of afterhours primary medical care services on clinical outcome, medical workload, and patient and GP satisfaction", Family Practice, Vol. 20, No. 3, pp. 311-317. doi:10.1093/fampra/cmg313

Leutgeb, R., et al. (2014), "On a European collaboration to identify organizational models, potential shortcomings and improvement options in out-of-hours primary health care", European Journal of General Practice, Vol. 20, No. 3, pp. 233-237. doi:10.3109/13814788.2014.887069

McKinlay, J.B. and L.D. Marceau (2012), "From cottage industry to a dominant mode of primary care: Stages in the diffusion of a health care innovation (retail clinics)", Social Science \& Medicine, Vol. 75, No. 6, pp. 1134-1141. doi:10.1016/j.socscimed.2012.04.039

McKinley, R.K., et al. (1997), "Comparison of out of hours care provided by patients' own general practitioners and commercial deputising services: a randomised controlled trial. II: the outcome of care", BMJ, Vol. 314, No. 7075, pp. 190-193.

Maheswaran, R., et al. (2007), "Impact of NHS walk-in centres on primary care access times: ecological study”, BMJ, 2007;334:838. doi:10.1136/bmj.39122.704051.55

Mason, S., et al. (2007), "Effectiveness of paramedic practitioners in attending 999 calls from elderly people in the community: cluster randomised controlled trial", $B M J, 2007 ; 335: 919$. doi:10.1136/bmj.39343.649097.55

Mehrotra, A., et al. (2009), "The costs and quality of care for three common illnesses at retail clinics as compared to other medical settings", Annals of Internal Medicine, Vol. 151, No. 5, pp. 321-328.

Monitor (2014), Walk-in centre review: final report and recommendations.

Moth, G., et al. (2014), "Drug prescription by telephone consultation in Danish out-of-hours primary care: a population-based study of frequency and associations with clinical severity and diagnosis", $B M C$ Family Practice, 15:142. doi:10.1186/1471-2296-15-142

Munro, J., F. Sampson and J. Nicholl (2005), "The impact of NHS Direct on the demand for out-of-hours primary and emergency care", British Journal of General Practice, Vol. 55, No. 519, pp. 790-792.

NACHC - National Association of Community Health Centers (2013), Expanding Access to Primary Care: The Role of Nurse Practitioners, Physician Assistants, and Certified Nurse Midwives in the 
Health Center Workforce. Fact Sheet Septembre 0913, available at: https://www.nachc.com/client/documents/Workforce_FS_0913.pdf

National Audit Office (2014), Out-of-hours GP services in England, Department of Health and NHS England, London.

Naylor, M. D. and E.T. Kurtzman (2010), "The Role Of Nurse Practitioners In Reinventing Primary Care", Health Affairs, Vol. 29, No. 5, pp. 893-899. doi:10.1377/hlthaff.2010.0440

NGA - National Governors Association (2012), The role of nurse practitioners in meeting increasing demand for primary care, NGA Paper, available at: http://www.nga.org/cms/home.

NHPA - National Health Performance Authority (2013), Healthy Communities: Australians' Experiences with Primary Health Care in 2010-11.

OECD (2016), OECD Reviews of Health Care Quality: United Kingdom 2016: Raising Standards, OECD Publishing, Paris. http://dx.doi.org/10.1787/9789264239487-en

O'Malley, A.S., et al. (2012), "After-hours care and its coordination with primary care in the US", Journal of General Internal Medicine, Vol. 27, No. 11, pp. 1406-1415. doi:10.1007/s11606-012-2087-4

O’Malley, A.S. (2013), “After-hours access to primary care practices linked with lower emergency department use and less unmet medical need", Health Affairs, Vol. 32, No. 1, pp. 175-183. doi:10.1377/hlthaff.2012.0494

O’Meara, P. and R. Strasser (2002), “Moe After Hours Medical Service: 'pillars' of success”, Australian Health Review, Vol. 25, No. 2, pp. 104-114.

Parker, R., et al. (2011), Independent Evaluation of the Nurse-Led ACT Health Walk-In Centre, Australian Primary Health Care Research Institute, Australian National University, Canberra, Australia.

Patwardhan, A., et al. (2012), "After-hours access of convenient care clinics and cost savings associated with avoidance of higher-cost sites of care", Journal of Primary Care \& Community Health, Vol. 3 , No. 4, pp. 243-245. doi:10.1177/2150131911436251

Pinchbeck, T. (2014), Walk This Way: Estimating Impacts of Walk in Centres at Hospital Emergency Departments in the English National Health Service, SERC Discussion Paper 167.

Põlluste, K., et al., (2013), "Primary care in Baltic countries: A comparison of progress and present systems”, Health Policy, Vol. 109, No. 2, pp.122-130. doi:10.1016/j.healthpol.2012.08.015

Pooley, C.G., et al. (2003), "Contacting your GP when the surgery is closed: issues of location and access", Health and Place, Vol. 9, No. 1, pp. 23-32. doi:10.1016/S1353-8292(02)00027-8

Raknes, G., E. Holm Hansen and S. Hunskaar (2013), "Distance and utilisation of out-of-hours services in a Norwegian urban/rural district: an ecological study", BMC Health Services Research, 13:222. doi:10.1186/1472-6963-13-222

Salisbury, C. (1997), "Evaluation of a general practice out of hours cooperative: a questionnaire survey of general practitioners", BMJ, Vol. 314, No. 7094, pp. 1598-1599. 
Salisbury, C. (2000), “The demand for out-of-hours care from GPs: a review”, Family Practice, Vol. 17, No. 4, pp. 340-347. doi:10.1093/fampra/17.4.340

Salisbury, C., et al. (2002), The National Evaluation of NHS Walk-in Centres, University of Bristol.

Salisbury, C. (2003), "Do NHS walk-in centres in England provide a model of integrated care?" International Journal of Integrated Care, 3:e18.

Schoen, C., et al. (2011), "New 2011 survey of patients with complex care needs in eleven countries finds that care is often poorly coordinated", Health Affairs, Vol. 30, No. 12, pp. 2437-2448. doi:10.1377/hlthaff.2011.0923

Schoen, C., et al. (2012), "A survey of primary care doctors in ten countries shows progress in use of health information technology, less in other areas", Health Affairs, Vol. 31, No. 12, pp. 2805-2816. doi:10.1377/hlthaff.2012.0884

Smith, S., et al. (2001), "Patients' views on out-of-hours care in general practice in Dublin", Irish Journal of Medical Science, Vol. 170, No. 3, pp. 192-194.

Starfield, B. (2000), "Is US health really the best in the world?" JAMA, Vol. 284, No. 4, pp. 483-485. doi:10.1001/jama.284.4.483

Tan, S. and N. Mays (2014), "Impact of initiatives to improve access to, and choice of, primary and urgent care in the England: a systematic review", Health Policy, Vol. 118, No. 3, pp. 304-315. doi:10.1016/j.healthpol.2014.07.011

Tenbensel, T., et al. (2013), Evaluation of Auckland Regional After-Hours Network and the After-hours Initiative, Phase 1 Evaluation Report, University of Auckland/Synergia.

Tenbensel, T., et al. (2014), Evaluation of A\&M, HML Telephone Triage, and St John Transport Initiatives, University of Auckland, New Zealand.

Thijssen, W.A.M.H., et al. (2013), "The impact on emergency department utilization and patient flows after integrating with a general practitioner cooperative: an observational study", Emergency Medicine International, Article ID 364659. doi:10.1155/2013/364659

Thompson, K., K. Parahoo and B. Farrell (2004), "An evaluation of a GP out-of-hours service: meeting patient expectations of care", Journal of Evaluation in Clinical Practice, Vol. 10, No. 3, pp. 467474. doi:10.1111/j.1365-2753.2004.00446.x

Turnbull, J., et al. (2008), "Does distance matter? Geographical variation in GP out-of-hours service use: an observational study", The British Journal of General Practice, Vol. 58, No. 552, pp. 471-477.

Turner, J., et al. (2012), Evaluation of NHS 111 pilot sites, University of Sheffield.

Turner, J., et al. (2013), "Impact of the urgent care telephone service NHS 111 pilot sites: a controlled before and after study", BMJ Open; 3:e003451. doi:10.1136/bmjopen-2013-003451

Van Uden, C.J.T., et al. (2005a), "The impact of a primary care physician cooperative on the caseload of an emergency department: the Maastricht integrated out-of-hours service", Journal of General Internal Medicine, Vol. 20, No. 7, pp. 612-617. doi:10.1111/j.1525-1497.2005.0091.x 
Van Uden, C.J.T., et al. (2005b), "Patient satisfaction with out-of-hours primary care in the Netherlands", BMC Health Services Research, 5(1):6. doi:10.1186/1472-6963-5-6

Victorian Auditor-General (2010), Delivery of Nurse-on-Call, Victoria, Australia.

Warren, F.C., et al. (2015), "Characteristics of service users and provider organisations associated with experience of out of hours general practitioner care in England: population based cross sectional postal questionnaire survey", BMJ, 350:h2040. doi:10.1136/bmj.h2040

Weaver, R.G., et al. (2014), "Access to primary care and other health care use among western Canadians with chronic conditions: a population-based survey", CMAJ Open, 2(1):E27-E34. doi:10.9778/cmajo.20130045

Wijers, N., et al. (2012), "The effectiveness of nurse practitioners working at a GP cooperative: a study protocol”, BMC Family Practice, 13:75. doi:10.1186/1471-2296-13-75

WHO - World Health Organization (2008), Primary Health Care: Now More Than Ever, The World Health Report 2008, Geneva, Switzerland. 
DELSA/HEA/WD/HWP(2016)12

\section{ANNEX}

\section{ANNEX A1. OECD POLICY SURVEY ON THE DELIVERY OF OUT-OF-HOURS PRIMARY CARE SERVICES}

\section{Organisation, planning and delivery of $\mathrm{OOH}$ primary care services}

1.1. Primary care services include first contact services for diagnosis and treatment of acute and chronic illnesses, health promotion, disease prevention, health maintenance, counselling, and patient education, in a variety of health care settings. These services can be provided by - although are not limited to - primary care physicians and nurses. How is primary care defined in your health system?

1.2. $\mathrm{OOH}$ primary care is often defined as health care provided from $5 \mathrm{pm}$ to $8 \mathrm{am}$ on weekdays, and on weekends and public holidays, for conditions that can be safely managed in primary care.

Is this how your health system defines $\mathrm{OOH}$ primary care? If not, please provide a detailed definition of $\mathrm{OOH}$ primary care. What criteria are used to define it (e.g. time range, extra fee for providers, etc.)?

What are the main aims of $\mathrm{OOH}$ primary care in your health system (e.g. primarily to respond to demand for "emergency needs" as perceived by patients, or to offer more flexibility and choice to patients for primary care services even without the need for "emergency" care)?

1.3. How is $\mathrm{OOH}$ primary care provided in your health system (please fill in the table below)?

If a patient needs $\mathrm{OOH}$ primary care, what is the typical pathway to access services? (Please note that the models presented in the table below are not mutually exclusive. If a particular type of provider is more likely to be found in certain areas (e.g. rural vs urban), please specify.) 


\begin{tabular}{|c|c|c|c|}
\hline Models & $\begin{array}{l}\text { Please provide details } \\
\text { of the circumstances } \\
\text { in which these services } \\
\text { are accessed (e.g. } \\
\text { rural and/or urban } \\
\text { areas, and the type of } \\
\text { services provided) }\end{array}$ & $\begin{array}{l}\text { To what extent is this } \\
\text { OOH service used } \\
\text { (please provide data if } \\
\text { available, otherwise } \\
\text { just mention whether it } \\
\text { is frequent or } \\
\text { marginal) }\end{array}$ & $\begin{array}{l}\text { Does your health } \\
\text { system promote the use } \\
\text { of this model, or } \\
\text { discourage its use for } \\
\text { OOH primary care? }\end{array}$ \\
\hline \multicolumn{4}{|l|}{$\begin{array}{l}\text { Physicians in individual } \\
\text { or group practices look } \\
\text { after their own patients } \\
\mathrm{OOH}\end{array}$} \\
\hline \multicolumn{4}{|l|}{$\begin{array}{l}\text { Rota groups in which } \\
\text { physicians take turns } \\
\text { being on OOH duty }\end{array}$} \\
\hline \multicolumn{4}{|l|}{$\begin{array}{l}\text { Deputising } \\
\text { contracted by practices to } \\
\text { provide OOH primary } \\
\text { care (e.g. commercial } \\
\text { companies } \\
\text { doctors and nurses) }\end{array}$} \\
\hline \multicolumn{4}{|l|}{$\begin{array}{ll}\text { Hospital } & \text { emergency } \\
\text { departments } & \end{array}$} \\
\hline \multicolumn{4}{|l|}{$\begin{array}{l}\text { Telephone-based services } \\
\text { to provide OOH medical } \\
\text { advice }\end{array}$} \\
\hline \multicolumn{4}{|l|}{$\begin{array}{lr}\text { After-hours } & \text { walk-in } \\
\text { primary } & \text { care } \\
\text { centres/minor } & \text { injury } \\
\text { units/urgent care centres }\end{array}$} \\
\hline \multicolumn{4}{|l|}{$\begin{array}{l}\text { Primary care or general } \\
\text { practitioner cooperatives, } \\
\text { in which providers in a } \\
\text { region form large-scale } \\
\text { groups, to provide OOH } \\
\text { primary care }\end{array}$} \\
\hline \multicolumn{4}{|l|}{$\begin{array}{l}\text { Retail or medical clinics } \\
\text { located within retail } \\
\text { stores (grocery stores or } \\
\text { pharmacies) staffed by } \\
\text { nurse practitioners or } \\
\text { other health professionals }\end{array}$} \\
\hline \multicolumn{4}{|l|}{$\begin{array}{l}\text { Telemedicine } \\
\text { consultations or other } \\
\text { video technology }\end{array}$} \\
\hline Others $^{4}$ & & & \\
\hline
\end{tabular}

4. In some countries, for example, primary care physicians give their personal phone numbers to patients and also correspond after hours via email with their patients. 
1.4. Apart from these options, is there a telephone triage line or a website that aims to direct patients to the appropriate $\mathrm{OOH}$ primary care service? If so, please provide details. How are patients informed about access to $\mathrm{OOH}$ primary care services?

1.5. Among these models, what is the predominant mode of provision of $\mathrm{OOH}$ primary care in your health system? (Please specify if the type of provision is more likely to be found in certain areas - e.g. rural vs urban).

1.6. For the predominant mode of provision $(\mathrm{ONLY})$ of $\mathrm{OOH}$ primary care, please explain:

a. Who is responsible for ensuring provision of this service (the national/central government, regional/state governments, local/municipal governments, individual providers or other private stakeholders)?

b. Who is the main financing agent (the national/central government, regional/state governments, local/municipal governments, social health insurance, or private health insurance)? Is it the same as for primary care services during standard working hours?

c. How are services paid to primary care providers (e.g. fee-for-service, extra fees, fixed amount, pay-for-performance, or other payment systems)?

d. Is it compulsory for primary care physicians to participate in the provision of $\mathrm{OOH}$ primary care services? If it is voluntary, has your health system measured the extent to which they participate? Please provide details and references.

e. Are physicians given financial incentives to participate in $\mathrm{OOH}$ service provision (e.g. do providers earn more and if so, what do they get?)

f. Are non-financial incentives given to primary care physicians to encourage their participation (such as authorities providing free space in facilities, assistance with information technology or other infrastructure)?

g. To what extent are nurse practitioners and physician assistants used in the predominant model of $\mathrm{OOH}$ primary care? Are they used as a substitution for primary care physicians, or do they complement medical services?

h. What strategies are in place to encourage continuity of patient care between $\mathrm{OOH}$ primary care and the regular primary care physician?

1.7. Are physicians working in hospitals permitted to provide $\mathrm{OOH}$ care services in the community? If so, what proportion of physicians work in hospitals as well as in the community?

1.8. Are patients required to pay and to share the costs of OOH primary care services? (For each model of $\mathrm{OOH}$ primary care present in your health system, please fill in the table below.) 


\begin{tabular}{|c|c|c|c|}
\hline Models & $\begin{array}{l}\text { Do patients receive } \\
\text { OOH primary care } \\
\text { free at the point of } \\
\text { care? If not, do they } \\
\text { pay the full cost of } \\
\text { OOH services (and } \\
\text { get reimbursed } \\
\text { afterwards) or do } \\
\text { they only pay user } \\
\text { fees or co-payments? }\end{array}$ & $\begin{array}{l}\text { Is the cost borne by } \\
\text { users different to what } \\
\text { they pay for primary } \\
\text { care services during } \\
\text { standard working } \\
\text { hours? Does it depend } \\
\text { on the circumstances } \\
\text { (e.g. "real emergency" } \\
\text { as assessed by the } \\
\text { provider)? }\end{array}$ & $\begin{array}{l}\text { If patients are required } \\
\text { to share the costs of } \\
\text { OOH primary care, } \\
\text { please provide the type } \\
\text { and level of cost- } \\
\text { sharing requirements } \\
\text { for an adult not subject } \\
\text { to any specific } \\
\text { exemption rule }\end{array}$ \\
\hline \multicolumn{4}{|l|}{$\begin{array}{l}\text { Physicians in individual or } \\
\text { group practices look after } \\
\text { their own patients } \mathrm{OOH}\end{array}$} \\
\hline \multicolumn{4}{|l|}{ Rota groups } \\
\hline \multicolumn{4}{|l|}{ Deputising services } \\
\hline \multicolumn{4}{|l|}{$\begin{array}{ll}\begin{array}{l}\text { Hospital } \\
\text { departments }\end{array} & \text { emergency } \\
\end{array}$} \\
\hline \multicolumn{4}{|l|}{ Telephone-based services } \\
\hline \multicolumn{4}{|l|}{$\begin{array}{l}\text { After-hours walk-in } \\
\text { primary care centres/minor } \\
\text { injury units/urgent care } \\
\text { centres }\end{array}$} \\
\hline \multicolumn{4}{|l|}{$\begin{array}{l}\text { Primary care or general } \\
\text { practitioner cooperatives }\end{array}$} \\
\hline \multicolumn{4}{|l|}{ Retail or medical clinics } \\
\hline \multicolumn{4}{|l|}{$\begin{array}{l}\text { Telemedicine consultations } \\
\text { or other video technology }\end{array}$} \\
\hline Others & & & \\
\hline
\end{tabular}

\section{Assessment of $\mathrm{OOH}$ primary care services}

2.1. Are there geographical differences in the organisation of $\mathrm{OOH}$ services (e.g. number of GPs involved in $\mathrm{OOH}$ primary care, number of $\mathrm{OOH}$ facilities, number of cars available for home visits, and the use of other clinical staff to support GPs)?

2.2. Are strategies in place to redress these geographical discrepancies? If so, please describe.

2.3. What strategies have been implemented to secure $\mathrm{OOH}$ primary care for under-served populations such as socially or economically-disadvantaged populations and migrant populations?

2.4. Has there been resistance from health professionals to participate in $\mathrm{OOH}$ primary care? If so, please specify the main reasons. Please provide details and references.

2.5. Have $\mathrm{OOH}$ primary care services been evaluated in your health system? If so, what are the strengths and weaknesses of existing $\mathrm{OOH}$ primary care services? Please provide details, reports and references.

5. If there is no cost-sharing, please indicate "no cost-sharing". Examples of other replies could be "copayment of $€ 2$ per visit"; "co-insurance of $20 \%$ "; "not reimbursed if not referred by a triage service", "copayment of $€ 20$ if the visit is considered inappropriate as assessed by the provider". 
2.6. Has an information campaign or educational intervention been used to increase public awareness on how to obtain appropriate $\mathrm{OOH}$ medical services? Please provide details, including any evaluations of impact.

\section{Evolution of $\mathrm{OOH}$ primary care services}

3.1. Are there any plans to implement other policies and/or models of $\mathrm{OOH}$ primary care in your health system? If so, what are they? Please provide details.

3.2. What are the main reasons for change?

3.3. What are the expected effects of future models? 
ANNEX A2. NUMBER OF COUNTRIES REPORTING DOMINANT OOH PRIMARY CARE MODELS

\begin{tabular}{|l|c|c|}
\hline & Number of countries & $\begin{array}{c}\text { Number of countries which also } \\
\text { report ED as a dominant model }\end{array}$ \\
\hline Practice-based services & 8 & 6 \\
\hline Rota groups & 9 & 5 \\
\hline Deputising services & 1 & 0 \\
\hline Hospital emergency departments & 15 & n.a. \\
\hline Primary care centres & 9 & 3 \\
\hline General practice cooperatives & 3 & 0 \\
\hline Retail clinics & 0 & 0 \\
\hline
\end{tabular}




\section{OECD HEALTH WORKING PAPERS}

A full list of the papers in this series can be found on the OECD website: http://www.oecd.org/els/health-systems/health-workingpapers.htm

No. 88 HEALTH CARE COVERAGE IN OECD COUNTRIES IN 2012 (2016) Valérie Paris, Emily Hewlett, Ane Auraaen, Jan Alexa, Lisa Simon

No. 87 PHARMACEUTICAL EXPENDITURE AND POLICIES: PAST TRENDS AND FUTURE CHALLENGES (2016) Annalisa Belloni, David Morgan, Valérie Paris

No. 86 THE LABOUR MARKET IMPACTS OF OBESITY, SMOKING, ALCOHOL USE AND RELATED CHRONIC (2016) Marion Devaux, Franco Sassi

No. 85 INTERNATIONAL COMPARISON OF SOUTH AFRICAN PRIVATE HOSPITALS PRICE LEVELS (2015) Luca Lorenzoni, Tomas Roubal

No. 84 PUBLIC EXPENDITURE PROJECTIONS FOR HEALTH AND LONG-TERM CARE FOR CHINA UNTIL 2030 (2015) Luca Lorenzoni, David Morgan, Yuki Murakami and Chris James*

No. 83 EMERGENCY CARE SERVICES: TRENDS, DRIVERS AND INTERVENTIONS TO MANAGE THE DEMAND (2015) Caroline Berchet

No. 82 MENTAL HEALTH ANALYSIS PROFILES (MhAPs) Sweden (2015) Pauliina Patana

No. 81 MENTAL HEALTH ANALYSIS PROFILES (MhAPs) England (2015) Emily Hewlett and Kierran Horner

No. 80 ASSESSING THE IMPACTS OF ALCOHOL POLICIES (2015) Michele Cecchini, Marion Devaux, Franco Sassi

No. 79 ALCOHOL CONSUMPTION AND HARMFUL DRINKING: TRENDS AND SOCIAL DISPARITIES ACROSS OECD COUNTRIES (2015) Marion Devaux and Franco Sassi

No. 78 TAPERING PAYMENTS IN HOSPITALS - EXPERIENCES IN OECD COUNTRIES (2015) Grégoire de Lagasnerie, Valérie Paris, Michael Mueller, Ankit Kumar

No. 77 WAGE-SETTING IN THE HOSPITAL SECTOR (2014) James Buchan, Ankit Kumar, Michael Schoenstein

No. 76 HEALTH, AUSTERITY AND ECONOMIC CRISIS: ASSESSING THE SHORT-TERM IMPACT IN OECD COUNTRIES (2014) Kees van Gool and Mark Pearson

No. 75 COMPARING HOSPITAL AND HEALTH PRICES AND VOLUMES INTERNATIONALLY (2014) Francette Koechlin, Paul Konijn, Luca Lorenzoni, Paul Schreyer

No. 74 MENTAL HEALTH ANALYSIS PROFILES (MhAPS) Scotland (2014) Alessia Forti

No. 73 MENTAL HEALTH ANALYSIS PROFILES (MhAPs) Netherlands (2014) Alessia Forti, Chris Nas, Alex van Geldrop, Gedrien Franx, Ionela Petrea, Ype van Strien, Patrick Jeurissen

No. 72 MENTAL HEALTH ANALYSIS PROFILES (MhAPs) Finland (2014) Pauliina Patana 


\section{RECENT RELATED OECD PUBLICATIONS}

BETTER WAYS TO PAY FOR HEALTH CARE (2016)

OECD HEALTH STATISTICS 2016 (Database available from http://www.oecd.org/health/health-data.htm)

HEALTH WORKFORCE POLICIES IN OECD COUNTRIES: RIGHT JOBS, RIGHT SKILLS, RIGHT PLACES (2016)

OECD REVIEWS OF HEALTH CARE QUALITY: UNITED KINGDOM (2016)

OECD REVIEWS OF HEALTH SYSTEMS: MEXICO (2016)

OECD REVIEWS OF HEALTH SYSTEMS: COLOMBIA (2016)

HEALTH AT A GLANCE (2015)

HEALTH DATA GOVERNANCE: PRIVACY, MONITORING AND RESEARCH (2015)

FISCAL SUSTAINABILITY OF HEALTH SYSTEMS: BRIDGING HEALTH AND FINANCE PERSPECTIVES (2015)

ADDRESSING DEMENTIA - THE OECD RESPONSE (2015)

CARDIOVASCULAR DISEASE AND DIABETES - POLICIES FOR BETTER HEALTH AND QUALITY OF CARE (2015)

DEMENTIA RESEARCH AND CARE: CAN BIG DATA HELP? (2015)

FIT MIND, FIT JOB - FROM EVIDENCE TO PRACTICE IN MENTAL HEALTH AND WORK (2015)

OECD HEALTH STATISTICS 2015 (Database available from http://www.oecd.org/health/healthdata

TACKLING HARMFUL ALCOHOL USE - ECONOMICS AND PUBLIC HEALTH POLICY (2015)

MAKING MENTAL HEALTH COUNT: THE SOCIAL AND ECONOMIC COSTS OF NEGLECTING MENTAL HEALTH CARE (2014)

HEALTH AT A GLANCE: EUROPE (2014)

HEALTH AT A GLANCE: ASIA/PACIFIC (2014)

GEOGRAPHIC VARIATIONS IN HEALTH CARE: WHAT DO WE KNOW AND WHAT CAN BE DONE TO IMPROVE HEALTH SYSTEM PERFORMANCE? (2014)

PAYING FOR PERFORMANCE IN HEALTH CARE: IMPLICATIONS FOR HEALTH SYSTEM PERFORMANCE AND ACCOUNTABILITY (2014)

OBESITY HEALTH UPDATE (2014)

http://www.oecd.org/els/health-systems/Obesity-Update-2014.pdf (electronic format only)

OECD REVIEWS OF HEALTH CARE QUALITY: AUSTRALIA (2015)

OECD REVIEWS OF HEALTH CARE QUALITY - JAPAN (2015)

OECD REVIEWS OF HEALTH CARE QUALITY - ITALY (2015)

OECD REVIEWS OF HEALTH CARE QUALITY - PORTUGAL (2015)

OECD REVIEWS OF HEALTH CARE QUALITY - CZECH REPUBLIC (2014)

OECD REVIEWS OF HEALTH CARE QUALITY - NORWAY (2014)

OECD REVIEWS OF HEALTH CARE QUALITY - TURKEY (2014)

For a full list, consult the OECD On-Line Bookstore at www.oecd.org, or write for a free written catalogue to the following address:

OECD Publications Service, 2, rue André-Pascal, 75775 PARIS CEDEX 16 or to the OECD Distributor in your country 